\title{
Natural antimicrobial agents
}

\section{Catarina Mirandela da Costa Gabriel}

\author{
Supervisor: Eng $^{\mathrm{a}}$ Cândida Miranda \\ Co-Supervisor: Prof. Manuel Simões \\ Co-Supervisor: Rita Fulgêncio
}

Mestrado Integrado em Bioengenharia especializaçáo em Engenharia Biológica 
(C) Catarina Mirandela da Costa Gabriel: June, 2017 
Faculdade de Engenharia da Universidade do Porto

Natural antimicrobial agents

\author{
Catarina Mirandela da Costa Gabriel
}

Dissertation submitted to Faculdade de Engenharia da Universidade do Porto to obtain the degree of

Master in Bioengineering

June, 2017 



\section{Abstract}

Customers' needs change along the years and currently the search for "cleaner" products is in vogue. Hence, the emergence of natural antimicrobials to substitute chemically synthesized preservatives like potassium sorbate or nitrites to ensure microbiological stability and prevent spoilage in food products is a must. New natural antimicrobials have appeared like enzymes, fermentates, liquid smoke, citrus extracts, vanillin and hydrosols. Many in situ and in vitro studies regarding their antimicrobial activity have been conducted and proved their potential use as preservatives in food duo to their bioactive properties. The aim of this project was to test the potential of some natural antimicrobials as a substitute of potassium sorbate, a preservative used at FRULACT, in fruit preparations and consequently in dosed yogurts.

Different antimicrobials such as lactoperoxidase, a fermented syrup, 2 liquid smokes, 2 citrus extracts, vanillin and an olive hydrosol were tested for their antifungal activity in vitro against fungi isolated in past work done at FRULACT. Vanillin and an organic citrus extract were the ones with greater antifungal activity and were selected for further tests. These natural preservatives were incorporated into fruit preparations and respective dosed yogurt and the respective microbial load was monitored as well as the stability of the lactic cultures in yogurt. Neither of the antimicrobials interfere with the natural microflora of the yogurts during 16 days of cold storage at $4{ }^{\circ} \mathrm{C}$. However only vanillin maintained its stability during the pasteurization process held at $90{ }^{\circ} \mathrm{C}$ for $4 \mathrm{~min}$ and was able to maintained the fungal safety of the fruit preparations and respective yogurt. It was also able to control an artificial contamination of an inoculum with an initial load of 5.06 $\log 10(\mathrm{CFU} / \mathrm{mL})$ constituted by Penicillum sp. and Aspergillus sp.. On the other hand, the organic citrus extract was not able to control the purpose contamination and was not resistant the pasteurization process. If added after the limiting step, the pasteurization, it could control the fungal load of the fruit and respective yogurt for at least 44 days and 16 days respectively during cold storage at $4{ }^{\circ} \mathrm{C}$. Lactoperoxidase was also tested in a different fruit preparation, FruIdentity, that was not subjected to a pasteurization process, and even though it controlled the fungal load in the preparation and did not interfere with the stability of the lactic cultures it was not able to control the fungal load in the respective dosed yogurt.

Keywords: natural antimicrobials, enzymes, liquid smoke, fermentates, vanillin, hydrosols, antifungal activity 


\section{Resumo}

As necessidades dos consumidores alteram-se ao longo do tempo e correntemente a procura por produtos sem compostos artificiais está em voga. Sendo assim, agentes antimicrobianos naturais surgiram como potenciais substitutos dos conservantes sintéticos como o sorbato de potássio ou nitratos que garantem a estabilidade microbiológica e previnem a deterioração dos produtos alimentares. Novos agentes antimicrobianos têm emergido como enzimas, compostos fermentados, aromas de fumo, extratos cítricos, vanilina e hidrossóis. Diversos estudos in situ e in vitro foram realizados acerca do potencial antifúngico dos agentes antimicrobianos naturais em produtos alimentares dados as suas propriedade bioativas. O objetivo deste projeto foi testar o potencial de alguns antimicrobianos naturais com o intuito de substituir o sorbato potássio, o conservante usado na FRULACT em preparados de fruta e consequentemente aplicados em iogurte.

Diferentes agentes antimicrobianos como a lactoperoxidase, xarope fermentado, 2 aromas de fumo, 2 extratos cítricos, vanilina e um hidrossol de azeitona foram testados quanto à sua atividade antifúngica in vitro contra fungos anteriormente isolados na FRULACT. A vanilina e o extrato cítrico orgânico foram os agentes antimicrobianos que demostraram uma maior atividade antifúngica. Sendo assim, foram selecionados e incorporados em preparados de fruta e posteriormente aplicados em iogurte. A carga fúngica foi monitorizada bem como a estabilidade das culturas láticas. Ambos os antimicrobianos não interferiram na estabilidade das culturas láticas durante 16 dias de refregeração a 4 ${ }^{\circ} \mathrm{C}$. Porém, apenas a vanilina manteve a sua estabilidade durante o processo de pasteurização a $90{ }^{\circ} \mathrm{C}$ durante 4 min e foi capaz de controlar a carga fúngica de tanto os preparados de fruta como os respetivos iogurtes. Conseguiu também controlar uma contaminação artificial de um inóculo com uma carga inicial de $5.06 \log 10$ (CFU / mL) constituído por Penicillum sp. e Aspergillus sp.. Por outro lado, o extrato cítrico orgânico não foi capaz de manter a sua estabilidade durante o processo de pasteurização e controlar a contaminação articial. Aquando a sua adição após o passo limitante, a pasteurização, este composto consegue controlar a carga fúngica dos preparados de fruta durante pelo menos 44 dias de refrigeração a $4{ }^{\circ} \mathrm{C}$. A enzima lactoperoxidade foi também testada num preparado de fruta diferente, FruIdentity, um produto que não é sujeito a um processo de pasteurização, e embora a carga fúngica fosse controlada no preparado e não interferisse com as culturas láticas do iogurte este não é capaz de controlar a carga fúngica do respetivo iogurte.

Palavras chave: antimicrobianos naturais, enzimas, aromas de fumo, compostos fermentados, vanilina, hidrossóis e actividade antifungica 


\section{Acknowledgments}

First and foremost I would like to thank my supervisors Prof. Dr. Manuel Simões from the Faculty of Engineering of the University of Porto (FEUP) and Eng ${ }^{a}$. Cândida Miranda at FRULACT for giving me the opportunity and support to develop this work.

I express my eternal gratitude to Rita Fulgêncio for all her guidance, help, patience and especially for her friendship throughout this work even when she was in times of hurdle. I would also like to thank the innovation team at FRULACT, in particular my intern friends Luís, Sara, Ana Brandão, Ana Lúcia and Mariana for all the support and help in ruff times, good times and laughter shared together. Furthermore, to my good friend Isabel at the innovation department for all her help and coffee shared at dawn that made every morning a top of the morning.

Additionally I would like to thank the lab technicians Carla, Paula and Silvia from the Chemical department at FEUP for all the support and shared experiences thought this 5 years.

Particularly I would like to thank my wonderful friends, Mariana, Rita and João, the so called "Bioamiguinhos" for putting up with me, my temper and my hibernation periods though almost 5 years. Without you guys the lab work, all the reports and team work would have not been the same. I am very grateful to have met such wonderful people that I know I can count on.

Lastly I would like to think my unique mom for all her love and just being there helping me in life and my family for all the support and family reunions that made everything better.

Este trabalho foi em parte financiado pelos Projetos (i) POCI-01-0145-FEDER-006939 (Laboratório de Engenharia de Processos, Ambiente, Biotecnologia e Energia, UID/EQU/00511/2013) financiado pelo Fundo Europeu de Desenvolvimento Regional (FEDER), através do COMPETE 2020 - Programa Operacional Competitividade e Internacionalização (POCI) e por fundos nacionais através da Fundação para a Ciência e a Tecnologia I.P., (ii) NORTE-01-0145-FEDER-000005 - LEPABE-2-ECO-INNOVATION, financiado pelo Fundo Europeu de Desenvolvimento Regional (FEDER), através do COMPETE2020 - Programa Operacional Competitividade e Internacionalização (POCI) e Programa Operacional Regional do Norte (NORTE2020)

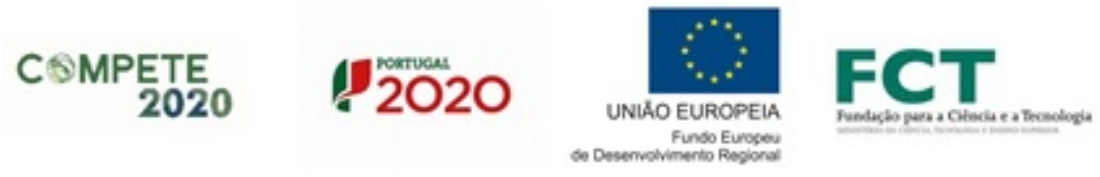




\section{Contents}

List of Figures $\quad$ xiii

List of Tables $\quad$ xvi

List of Abbreviations $\quad$ xvii

1 Work Outline 1

1.1 Thesis presentation . . . . . . . . . . . . . . . 1

1.2 Research objectives . . . . . . . . . . . . . . . . 2

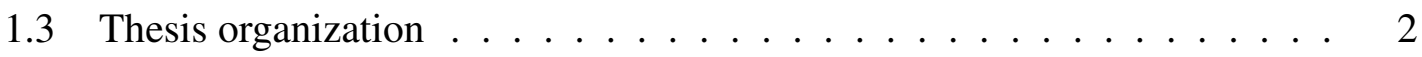

2 Theoretical Background 5

2.1 Clean label concept . . . . . . . . . . . . . . . . . . 5

2.2 Natural food antimicrobials . . . . . . . . . . . . . 6

2.3 Use of enzymes as antimicorbials . . . . . . . . . . . . . 7

2.3.1 Lysozyme . . . . . . . . . . . . . . . . . 7

2.3 .2 Lactoperoxidase . . . . . . . . . . . . . . 8

2.4 Use of fermentates as antimicrobials . . . . . . . . . . . . . . 9

2.5 Use of liquid smoke as antimicrobial . . . . . . . . . . . . . . 10

2.6 Use of antimicrobial from plant origin . . . . . . . . . . . . . . 13

2.6.1 Essential oils . . . . . . . . . . . . . . . . 13

2.6 .2 Citrus extract . . . . . . . . . . . . . . 14

2.6 .3 Vanillin ........................ 16

2.6 .4 Hydrosols . . . . . . . . . . . . . . . . . . 17

2.7 Challenges . . . . . . . . . . . . . . . . . . . 19

3 In vitro assessment of the antifungal activity of the natural antimicrobials 21

3.1 Introduction . . . . . . . . . . . . . . . . . 21

3.2 Materials and Methods . . . . . . . . . . . . . . 22

3.2.1 Maintenance of the isolated microorganisms . . . . . . . . 22

3.2 .2 Antimicrobials tested . . . . . . . . . . . . . 23

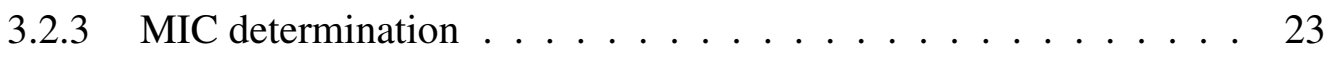

3.3 Results and discussion . . . . . . . . . . . . . . . . . . . 24

3.4 Conclusions . . . . . . . . . . . . . . . . . . 31 
4 Testing the selected natural antimicrobials in fruit preparations and yogurt 33

4.1 Introduction . . . . . . . . . . . . . . . . . . . 33

4.2 Materials and methods . . . . . . . . . . . . . . . 34

4.2.1 Forest fruit preparations . . . . . . . . . . . . . . 34

4.2.2 ${ }^{\mathrm{o}}$ Brix, $\mathrm{pH}$ and viscosity . . . . . . . . . . . . . 34

4.2.3 Simulation of an environmental contamination . . . . . . . 35

4.2.4 Resume table . . . . . . . . . . . . . . . 35

4.2.5 Microbiological analysis of the fruit preparations . . . . . . . 35

4.2 .6 Dosage in yogurt . . . . . . . . . . . . . . . . 36

4.2.7 Microbiological analysis of the yogurt . . . . . . . . . . . . . . 36

4.2.8 Evaluation of organoleptic properties . . . . . . . . . . . . 37

4.2 .9 Statistical analysis . . . . . . . . . . . . . . . 37

4.3 Results and discussion . . . . . . . . . . . . . . . . 37

4.3.1 Effect of vanillin and citrus extract in microbiology load of fruit

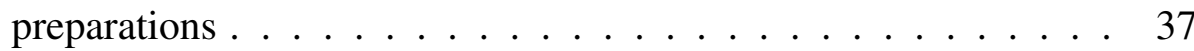

4.3.2 Effect of vanillin and citrus extract in artificially contaminated fruit preparations . . . . . . . . . . . . . 40

4.3.3 Effect of vanillin and citrus extract in microbiology load and lactic cultures in fruit preparations dosed in yogurts . . . . . . . . 43

4.3.4 Evaluation of the organoleptic properties . . . . . . . . . . 44

4.3 .5 Price analysis . . . . . . . . . . . . . . . 46 46

4.4 Conclusions . . . . . . . . . . . . . . . . . . 47

5 Testing lactoperoxidase in FruIdentity strawberry preparation and yogurt 49

5.1 Introduction . . . . . . . . . . . . . . . . . . . . . . 49

5.2 Materials and methods . . . . . . . . . . . . . . . 50

5.2.1 FruIdentity strawberry preparations . . . . . . . . . 5 50

5.2.2 Microbiological analysis of the fruit preparations . . . . . . . 50

5.2 .3 Dosage in yogurt . . . . . . . . . . . . . 51

5.2 .4 Microbiological analysis of the yogurt .......... 51

5.3 Results and discussion . . . . . . . . . . . . . . . . 52

5.3.1 Effect of lactoperoxidase in the microbiology load of FruIdentity strawberry preparations . . . . . . . . . . . . 52

5.3.2 Effect of lactoperoxidase in the microbiology load and lactic cultures in FruIdentity strawberry preparations dosed in yogurt . . . 53

5.4 Conclusions . . . . . . . . . . . . . . . . . 55

6 Conclusions and future work $\quad 57$

6.1 General conclusions . . . . . . . . . . . . . . . . 57

6.2 Future work . . . . . . . . . . . . . . . 58

References

$\begin{array}{ll}\text { Index } & 71\end{array}$ 
A In vitro assessment of the antifungal activity of the natural antimicrobials i

A.0.1 Tables of the isolated microorganisms ............ i i

B Testing the selected natural antimicrobials in fruit preparations and yogurt $v$

B.0.1 Questionnaire .................. v v 


\section{List of Figures}

3.1 Micelles formation observed in $70 \%(\mathrm{~V} / \mathrm{V})$ ethanol with a concentration of $1 \%(\mathrm{w} / \mathrm{V})$ olive hydrossol . . . . . . . . . . . . . . 26

3.2 Growth inhibition of Penicillium sp. at different concentrations of vanillin after 7 days incubation at $25{ }^{\circ} \mathrm{C} \ldots \ldots \ldots \ldots \ldots$

3.3 Mycelial growth inhibition of Penicillium sp. by $0.5 \%(w / \mathrm{V})$ of organic

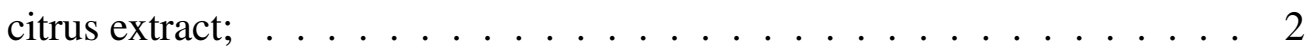

4.1 Aspect of the fruit preparations containing potassium sorbate, organic citrus extract, vanillin or no antimicrobial after 51 to 53 days of refrigerated

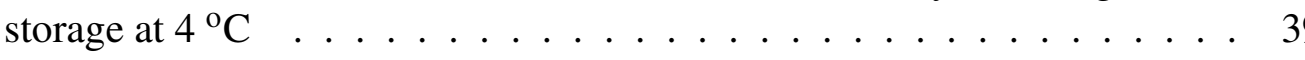

4.2 Fungal load of fruit preparations containing organic citrus extract, vanillin, potassium sorbate (control (+)) or no antimicrobial (control (-)) during 51 to 53 days of cold storage at $4{ }^{\circ} \mathrm{C}$. The bullet points represent the average values and the bars the standard deviation. "Citrus-after" and "Vanillin-after" represents the tendency of the fruit preparation where the natural antimicrobial was added after the pasteurization process. "Citrusbefore"and "Vanillin-before"represents the tendency of the fruit preparation where the natural antimicrobial was added before the pasteurization process. The red line represents the detection limit of the technique. . . . 40

4.3 Aspect of the fruit preparations containing organic citrus extract or vanillin after 25 and 52 days respectively of refrigerated storage at $4{ }^{\circ} \mathrm{C} \ldots \ldots$.

4.4 Fungal load of fruit preparations containing vanillin or organic citrus extract artificially contaminated over 52 or 25 days of cold storage at $4{ }^{\circ} \mathrm{C}$ respectively. The bullet points represent the average values and the bars the standard deviation. "Citrus-after" and "Vanillin-after" represents the tendency of the fruit preparation where the natural antimicrobial was added after the pasteurization process. "Citrus-before" and "Vanillin-before" represents the tendency of the fruit preparation where the natural antimicrobial was added before the pasteurization process. The red line represents the detection limit of the technique $\ldots \ldots \ldots \ldots \ldots$ 
4.5 L. bulgaricus load of fruit preparations in dosed in yogurt containing organic citrus extract, vanillin, potassium sorbate $(\mathrm{c}(+))$ or no antimicrobial (c (-)) during 23 days of cold storage at $4{ }^{\circ} \mathrm{C}$. The bars represent the average values and the bars the standard deviation. " $\mathrm{C}-\mathrm{A}$ " and "V-A" represents the tendency of the yogurt where the natural antimicrobial was added after the pasteurization process. "C-B"'and 'V-B"represents the tendency of the yogurt where the natural antimicrobial was added before the pasteurization process. "V-B-C", V-A-C" represents the tendency of the yogurt where the natural antimicrobial was added before or after the pasteurization process, , correspondingly and were artificially contaminated. The red line represents the detection limit of the technique . . . . . . .

4.6 Fungal load of fruit preparations in dosed in yogurt containing organic citrus extract, vanillin, potassium sorbate $(\mathrm{c}(+))$ or no antimicrobial $(\mathrm{c}$ (-)) during 23 days of cold storage at $4{ }^{\circ} \mathrm{C}$. The bars represent the average values and the bars the standard deviation. "C-A" and "V-A" represents the tendency of the yogurt where the natural antimicrobial was added after the pasteurization process. "C-B" and 'V-B"represents the tendency of the yogurt where the natural antimicrobial was added before the pasteurization process. "V-B-C", V-A-C" represents the tendency of the yogurt where the natural antimicrobial was added before or after the pasteurization process, , correspondingly and were artificially contaminated. The red line represents the detection limit of the technique. . . . . . . . . .

4.7 Perception of the tasters of acidity, sweetness, astringency and flavor when comparing the yogurts with fruit preparations containing vanillin or organic citrus extract with the standard (potassium sorbate) $\ldots . .$.

4.8 Preference of the tested subjects when comparing the yogurts with fruit preparations containing vanillin or organic citrus extract with the standard (potassium sorbate) . . . . . . . . . . . . . . . .

5.1 Fungal load of fruit preparations containing lactoperoxidase, potassium sorbate (controlo (+)) or no antimicrobial (control (-)) during 58, 57 and 56 days correspondingly of cold storage at $4{ }^{\circ} \mathrm{C}$. The bullet points represent the average values and the bars the standard deviation. The red line represents the detection limit of the technique. . . . . . . . . . . .

5.2 Aspect of the fruit preparations containing potassium sorbate, lactoperoxidase or no antimicrobial after 56 to 58 days of refrigerated storage at 4 ${ }^{\mathrm{o}} \mathrm{C} \ldots \ldots \ldots \ldots \ldots \ldots$

5.3 L. bulgaricus load of fruit preparations in dosed in yogurt containing lactoperoxidase, potassium sorbate (controlo (+)) or no antimicrobial (control (-)) during 23 days of cold storage at $4{ }^{\circ} \mathrm{C}$. The bullet points represent the average values and the bars the standard deviation. The red line represents the detection limit of the technique. . . . . . . . . . . . 
5.4 Fungal load of fruit preparations dosed in yogurt containing lactoperoxidase, potassium sorbate (controlo (+)) or no antimicrobial (control (-)) during 23 days of cold storage at $4{ }^{\circ} \mathrm{C}$. The bullet points represent the average values and the bars the standard deviation. The red line represents the detection limit of the technique. . . . . . . . . . . . . 55

B.1 Example of a questionnaire taken by the subjects when tasting the yogurt with the natural antimicrobials. Every person did two, one for the yogurt with the fruit preparation with vanillin and the one for the fruit preparation with the citrus extract. The questionnaires focus on the comparison of the fruit preparation with potassium sorbate with the ones containing the natural antimicrobials. 


\section{List of Tables}

2.1 The most common volatile compounds found in citrus fruit (adapted from (Moufida and Marzouk, 2003)) . . . . . . . . . . . . . . . 15

3.1 Natural antimicrobials studied, their physical state and respective supplier. The suppliers are not discriminated due to confidentiality clauses . .

3.2 Antifungal activity of the natural antimicrobials tested on yeasts after 7 days incubation at $25{ }^{\circ} \mathrm{C}$. MIC represents the minimal inhibitory concentration of each natural antimicrobial in $(\mathrm{w} / \mathrm{V}) \%$. RG represents the concentration at which there is a retarded growth of the colony when compared to the control in $(\mathrm{w} / \mathrm{V}) \%$. NA represents the compounds that did not show any antifungal activity against the tested microorganisms even at maximum concentrations of $0.5 \%(\mathrm{~m} / \mathrm{V}) \ldots \ldots \ldots$

3.3 Antifungal activity of the natural antimicrobials tested on fungus after 7 days incubation at $25{ }^{\circ} \mathrm{C}$. MIC represents the minimal inhibitory concentration of each natural antimicrobial in $(\mathrm{w} / \mathrm{V}) \%$. RG represents the concentration at which there is a retarded growth of the colony when compared to the control in $(\mathrm{w} / \mathrm{V}) \%$. NA represents the compounds that did not show any antifungal activity against the tested microorganisms even at maximum concentrations of $0.5 \%(\mathrm{~m} / \mathrm{V}) \ldots \ldots . \ldots 25$

4.1 Different components of the fruit preparations. The exact components are not revealed due to confidentiality clauses. The water percentage may suffer little changes depending on the antimicrobial added. . . . . . . . . . 35

4.2 Resume table of the different conditions tested in fruit preparations. The third column refers to the addition of the antimicrobials after or before the pasteurization process. - represents the situation where the variable indicated was not tested . . . . . . . . . . . . . 36

4.3 $\mathrm{pH},{ }^{\circ}$ Brix and viscosity values of the different fruit preparations done. The third column refers to the addition of the antimicrobials after or before the pasteurization process. - represents the situation where the variable indicated was not tested . . . . . . . . . . . . . . 38 
5.1 Different components of the FruIdentity strawberry.The exact components are not revealed due to confidentiality clauses. The antimicrobial refers to the potassium sorbate or lactoperoxidase that was added to different preparations. The water percentage may suffer little changes depending on the antimicrobial added. . . . . . . . . . . . . . . 50

A.1 Fungi isolated when characterizing raw materials and different zones Tortosendo Industry. The number correspondent to each plate is related with the source of isolation hence just being a reference. NI represents the fungi that could not be identified by RT-PCR. . . . . . . . . . . . . . ii

A.2 Yeasts isolated when characterizing raw materials and different zones Tortosendo Industry. The number correspondent to each plate is related with the source of isolation hence just being a reference. NI represents the microorganisms that could not be identified by RT-PCR. . . . . . . . . . iii 


\section{List of Abbreviations}

$\begin{array}{ll}\text { aw } & \text { Water activity } \\ \text { CFU } & \text { Colony forming units } \\ \text { DRBC } & \text { Dichloran-Rose Bengal Chloramphenicol } \\ \text { EO } & \text { Essential Oils } \\ \text { FDA } & \text { Food and Drug Administration } \\ \text { G.M.O } & \text { Genetically modified organism } \\ \text { GRAS } & \text { Generally recognized as safe } \\ \text { LAB } & \text { Lactic acid bacteria } \\ \text { MGI } & \text { Mycelial Growth Inhibition } \\ \text { MIC } & \text { Minimal inhibitory concentrations } \\ \text { MRS } & \text { Man Rogosa and Sharpe } \\ \text { PAH } & \text { Polycyclic aromatic hydrocarbons } \\ \text { PDA } & \text { Potato dextrose agar } \\ \text { SC } & \text { Sodium caseinate }\end{array}$





\section{Chapter 1}

\section{Work Outline}

\subsection{Thesis presentation}

This work was developed in colaboration with FRULACT. This is an agro-food company founded in 1987 in the north of Portugal, Maia. Later, the company expanded and currently has several industry units in Portugal (Maia, Ferro, Tortosendo), North and South Africa, France and Canada. It is responsible for producing fruit preparations for other industries such as ice-creams, pastry, beverages and others. However, their main area of focus is dairy products, since almost $90 \%$ of its clients are dairy industries.

To guaranty safe and quality products, FRULACT has several certifications in its 7 industrial units: ISO 9001:2008, ISO 22000:2005, NP ISO 14001:2012, BRC and NP 4457:2007.

The company has a strong reputation all over the world and its value was recognition by the many awards received. From 1998 to 2001 was awarded with 4 SME Excellence awards by IAPMEI and in more recent year, in 2013 received the award of Company of the Year, Excellens Oeconomia Prize by Pwc and Jornal de Notícias.

In 2012 Frutech (Agro Food Innovation Technology Centre) emerges, aiming to enhance client satisfaction, by developing new and innovating products and reducing new products time-to-market. It includes pilot plant facilities, Food Microbiology, Sensorial and Physico-chemical Labs for fruits and its derivates. More than 2000 R \& D projects were develop in this institution to promote new add value products such as fruit preparations enriched with calcium, plant extracts and omega 3 or vegetable preparations for the dairy industry (Frulact, 2016).

Consumer's views have change thought the years and nowadays they are looking for natural foods, without any chemically synthesized components or additives. To meet this recent trend FRULACT tends to changes the chemically derived substances for natural 
ones. Potassium sorbate, a chemical preservative is a great example. It is known for its capacity to retard the growth of spoilage fungi while maintaining the microbiological safety of the fruit preparations during the products shelf life and controlling possible environmental contaminations (Takahashi et al., 2011). In this way, the main objective of the present thesis is to substitute this additive for a natural one. Natural antimicrobials can have various sources, animals, microorganisms and plants. Vanllin, citrus extracts, hydrossols, fermentates, smoke aromas and enzymes are examples of natural antimicrobials that are going to be tested for their antimicrobial activity and potential use in fruit preparations done at FRULACT.

\subsection{Research objectives}

One of the principal objectives was to evaluate the potential substitution of potassium sorbate for a natural antimicrobial that can maintain its stability during the shelf life of the product, the pasteurization process and its microbiological safety. Hence, the natural antimicrobials were tested in fruit preparations that were further incorporated in yogurt. To facilitate understanding, the thesis was divided in this two main parts:

- Test the antifungal activity of the natural antimicrobials in vitro: the natural antimicrobials were tested against the most recurring yeasts and molds.

- Test the selected natural antimicrobials in the final product: The antimicrobials showing more antifungal activity were tested in fruit preparations and dosed in yogurt. Its stability during the pasteurization process was assessed as well as its capacity to control possible environmental contaminations. Since yogurt is considered to be functional food itself, the antimicrobils should not interfere with lactic acid bacteria present, so the effect of the antimicrobials on the viability of the yogurt natural microflora was analysed. Finally, the organoleptic properties were evaluated by a random panel of tasters.

\subsection{Thesis organization}

The present work is divided in 6 Chapters. The $1^{\text {st }}$ Chapter introduces the reader for the motivation behind the work, the main goals and gives an idea of what is going to be discussed throughout.

On Chapter 2 a literature review about different natural antimcrobials potential application on food industry is done. Mainly smoke aromas, vanillin, citrus extract and 
hydrossols from plant origin, enzymes from animal origin and fermentates from microorganisms are the main focus of this work. Challenges for their incorporation in food and in industrial processes are discussed.

Chapter 3 focus on in vitro studies to test the antifungal activity of the natural antimicrobials (vanillin, 2 citrus extracts, an olive hydrossol, lactoperoxidase and a fementated syrup). Once the best natural antimicrobials were selected they were tested in situ on Chapter's 4 and 5.

Both Chapter 4 and 5 test the effect of the incorporation of the selected antimicrobials in the final products in terms of microbiology and organoleptic propertied.

Chapters 34 and 5 and subdivided intro four parts. First a brief introduction which is followed by the materials and methods. Then the results and discussion that are followed by general conclusions.

Chapter 6 makes an overview of the developed work and provides some suggestions for future work. 


\section{Chapter 2}

\section{Theoretical Background}

\subsection{Clean label concept}

There is no one definition of clean label products, but it is commonly associated with words such as nature, simplicity, transparency and less processed. The "clean-label movement" is gaining importance as consumers focus on natural, fresh, non-G.M.O. (genetically modified organism), gluten-free food along with the absence of artificial colors, sweeteners, flavor enhancers, and preservatives. Starting to care more about how the foods are sourced and produced, consumers want shorter and more recognizable ingredients lists and manufactures began to respond by increasingly highlighting the naturalness and origins of their products (FI Europe, 2015; Bizzozeri, 2016; Hilton, 2016).

The need for "cleaner" products translates into changes across the entire spectrum starting by using familiar ingredients in new ways, utilizing manufacturing by-products to create new offerings and opportunities, developing new manufacturing techniques that can create natural alternatives to artificial ingredients or enhance product health benefits. Natural antimicrobials are easily available from various natural sources, such as plants, animals and microorganisms in which they constitute part of host defense mechanisms against microbial infections. Once discarded plant parts are now considered viable and can be capitalized upon (Hilton, 2016; Juneja et al., 2012).

Companies like Nestlé, Kellogg's, and other major food and beverage companies are committed to remove artificial ingredients. Mondelez International is one of the latest companies to commit to removing artificial colors and flavors from packaged food brands and increase transparency through front-of-pack labeling and easy access to nutritional information. It is also known that more than $40 \%$ of new products launched globally in 2014 had "G.M.O. free" labeling (Watrous, 2015). 


\subsection{Natural food antimicrobials}

One of the main concerns of the food industry is to deliver quality and safe food. The risk of contracting foodborne illnesses is reduced by several preservation methods: thermal processing, drying, freezing, refrigeration, irradiation, modified atmosphere packaging, and the addition of antimicrobial agents, salts, or other chemical preservatives. Unfortunately, these techniques cannot be applied to all food products because of undesired effects (texture, color, etc.) depending on food type and conventional synthetic chemical preservatives are heavily used. Substances including nitrates/nitrites, sulphites, sodium benzoate, propyl gallate sodium sorbate and potassium sorbate (Lee and Paik, 2016). Nevertheless, there are known side effects when consuming "chemical preservatives. The use of nitrates and nitrites, additives normally used as curing agents in meat products are suspected to cause stomach cancer (Sharma, 2015). The increasing demand for healthy food led to changes in the industry, processed food with minimal food additives and thermal treatment are required among consumers. Hence, natural antimicrobials emerged being able to extend shelf life of food by inhibiting the growth of microbial cells or by killing them (Juneja et al., 2012). The potential of utilizing natural antimicrobials in food, however methods and mechanisms of action, toxicological and sensory effects of natural antimicrobials are not totally understood (Tajkarimi et al., 2010).

As stated in the previous section, natural antimicrobials can have various natural sources: animals, microorganisms and plants. In order to be consider as such, they have to require some characteristics, be safe, stable during food processing ( $\mathrm{pH}$, heat, pressure), and antimicrobial efficient(Lee and Paik, 2016).

Several studies have been conducted in order to find natural antimicrobials from animal origin and numerous polypeptides like chitosan, magainin, pleurocidin, curvacin A and spheniscin are reported to have antimicrobial activity and potential application as food preservatives (Cole et al., 1997; Gänzle et al., 1999; Tiwari et al., 2009; Tikhonov et al., 2006). Chitosan, $\mathrm{CH}$, a collective group of all partially and fully deacetylated chitinous compounds, is a polycationic biopolymer present in the exoskeletons of crustaceans and arthropods (Tikhonov et al., 2006). Chitosan is safe for antimicrobial applications due to its low toxicity against animal cells, also having a large spectrum of antimicrobial activity against bacteria and fungi (Juneja et al., 2012). This polar molecule is frequently used in food processing to improve quality and shelf life of food. $\mathrm{CH}$ coating can be used to reduce bacterial contamination of egg contents (Leleu et al., 2011) . It can also be combined with the thermoplastic and film-forming properties of sodium caseinate (SC) to prepare SC-CH film-forming solutions and films that are successful in reducing the native microflora of cheese, salami, and carrots (Moreira et al., 2011) . 
Microorganisms can also produce compounds small enough, cationic, amphiphilic, membrane-permeabilizing peptides that have antimicrobial activity against a wide range of microorganisms. Bacteriocins are an example of antimicrobial peptides produced by Lactobacillus sp. that due to a heterologous subgroup of ribosomally synthesized cationic peptides have antimicrobial activities. Even though bacteriocins can inhibit pathogenic and food-spoilage bacteria, they are usually ineffective against Gram-negative bacteria because they cannot penetrate the bacterium's outer membrane. This can only be achieved by combining them with other preservation methods (organic acids, or other antimicrobials) (Juneja et al., 2012).

Lastly, plant parts, such as herbs and spices are traditionally used in food to add flavors and fragrances (Tajkarimi et al., 2010; Burt and Reinders, 2003; Tiwari et al., 2009). The antimicrobial activities of extract from several types of plants and plant parts used as flavoring agents in food and beverages have been recognized for many years (López-Malo et al., 1995; Rupasinghe et al., 2006). Products derived from plant parts, essential oils, phytoalexins, phenolic and related compounds, contain active ingredients that may act as antimicrobial compounds against bacteria, yeast and molds. Even though, the majority of EO are classified as GRAS (Generally recognized as safe) substances, the pungent flavor limits their use as preservatives in food. Saponins, flavonoids, carvacrol, thymol, citral, eugenol, linalool, terpenes and their precursors are the major groups of essential oils with antimicrobial characteristics, originated from various plant parts: leaves of basil and tea plants, bulbs of garlic and onion, cloves buds, seeds of parsley, and others (Juneja et al., 2012; Delves-Broughton, 2012).

Enzymes from animal origin, fermentates originated from the fermentation of substrates by microorganisms, liquid smoke, vanillin and hydrosols originated from plants are some natural antimicrobial agents that the present report focuses on.

\subsection{Use of enzymes as antimicorbials}

\subsubsection{Lysozyme}

Lysozyme, peptidoglycan $\mathrm{N}$-acetylmuramoyl hydrolase, is a traditional antimicrobial, nontoxic to humans which has been used for many years. Their use in food as natural antimicrobials has been approved in many countries. It can be added directly to food, since it is considered as a GRAS enzyme. This lytic enzyme is present in avian eggs, mammalian milk, tears and other secretions. The enzyme is most active from 55 to 60 ${ }^{\circ} \mathrm{C}$, nevertheless it remains up to $50 \%$ active at lower temperatures $\left(10-25^{\circ} \mathrm{C}\right.$ ) (Davidson et al., 2013; Juneja et al., 2012; Lucera et al., 2012). 
This enzyme catalyzes the hydrolysis of the $\beta$-1,4-glycosidic bond between $\mathrm{C}-1$ of $\mathrm{N}$ - acetylmuramic acid and $\mathrm{C}-4$ of $\mathrm{N}$-actylglucosamine, resulting in cell wall degradation and lysis in hypotonic systems. The enzyme is more active against gram-positive bacteria because the cell wall is more exposed like in Bacillus coagulans, Bacillus stearothermophilus, Micrococcus, Clostridium tyrobutyricum, and Thermoanaerobacterium thermossaccharolyticum. Gram-negative pathogens and spoilage bacteria are not sensitive to lyzoyme such as Aeromonas hydrophila, Brochothrix thermosphacta, Escherichia coli O157:H7, Salmonella Typhimurium, Shigella and Vibrio cholera (Davidson et al., 2013; Aziz and Karboune, 2016).

It has been reported that lysozyme is a strong preservative in alcoholic beverages, such as unpasteurized beer (Makki and Durance, 1996). In more recent years, ART FRESH 50/50, a commercially available lysozyme preparation was effective in controlling Listeria monytogenes growth in raw minced tuna and salmon (Takahashi et al., 2011). Another commercially available lysozyme, Inovapure from Neova ${ }^{T M}$ Technologies, was added to processed meat, milk, cheese and other dairy products consequently increasing its shelf life (Tiwari et al., 2009). Some modified variants of lysozyme were developed. A heatdenatured lysozyme, which has no enzymatic activity but does have antimicrobial activity, showed antimicrobial activity against a variety of bacteria and fungi (Düring et al., 1999). Even though lysozyme is consider to be a natural antimicrobial, if applied to food according to the European legislation it has be declared as an E compound, hence the clean label concept is violated if lysozyme where to be applied to food (European Parliament and Council of the European Union, 2008).

\subsubsection{Lactoperoxidase}

Lactoperoxidase, another animal origin protein, can be found naturally in milk, saliva and tears (Min and Krochta, 2005; Aziz and Karboune, 2016). The enzyme has a strong antimicrobial affect against Gram-negative and -positive bacteria and fungi catalysing the oxidation of thiocyanate ion using hydrogen peroxide $\left(\mathrm{H}_{2} \mathrm{O}_{2}\right)$ (Kussendrager and van Hooijdonk, 2000; Tiwari et al., 2009).The resulting products, hypothiocyanite and hypothiocyanous acid, exhibit an inhibitory effect on microorganisms by the oxidation of sulfhydrylgroups in their enzyme systems and proteins (Min and Krochta, 2005; Kussendrager and van Hooijdonk, 2000). The presence of the pseudohalogen thiocyanate or a halogen as a second substrate (electron donor) is required to exert this antimicrobial effect (Kussendrager and van Hooijdonk, 2000). The direct effect of lactoperoxidasesystem action on cell is the membrane damage resulting in loss of $\mathrm{pH}$ gradient, $\mathrm{K}^{+}$leakage, an inhibition of transport of solutes, such as amino acids and glucose (Elotmani 
and Assobhei, 2004). Hence, over the years, dairy, oral care, cosmetics, cancer and viral infection industries have been using it (Lee and Paik, 2016).

It was reported that lactoperoxidase system at concentrations superior to $0.1 \%(\mathrm{w} / \mathrm{w})$ inhibited Penicillium commune in a potato dextrose broth and $1 \%$ peptone water (Min and Krochta, 2005). Min et al. 2005 also reported that lactoperoxidase system in packaging films can inhibit completely Salmonella enterica and E. coli O157:H7 (at $4 \log 10 \mathrm{CFU}$ (colony forming units) $/ \mathrm{cm}^{2}$ ). These results indicate that films containing lactoperoxidase system can be used to decrease the risk of contamination (Min et al., 2005). Yener et al. 2009 also incorporated lactoperoxidase system into alginate films. The decreasing order of resistance of bacteria to lactoperoxidase was: E. coli, L. innocua and Pseudomonas fluorescens. Its inhibitory action depended on the activity of the enzyme and the concentrations of $\mathrm{H}_{2} \mathrm{O}_{2}$ (Yener et al., 2009).

\subsection{Use of fermentates as antimicrobials}

Fermentates are fermented food ingredients. They can be produced from a variety of materials, milk, sugar, whey and other plant derived materials. The fermentation is done using food-grade microorganisms like lactic acid bacteria (LAB) or propionic acid bacteria (PAC) that produces organic acids (lactic, acetic or propionic acid), diacetlyl or other inhibitory peptides (bacteriocins). For starter cultures, the common microorganisms are: Lactococcus lactis, Lactobacillus, Pediococcus and Propionibacterium freudenreichi subsp. Shermanii (Taylor, 2014; Elsser-Gravesen and Elsser-Gravesen, 2014; DelvesBroughton, 2012).

Fermentates are considered a complex mixture and do not have a well-defined composition. Thus, the efficacy of such fermenters, regardless of the source of organism, cannot be ascribed to a single antimicrobial factor, but to a combination of organic acids and antimicrobial peptides. However, the antimicrobial action of bacteriocins is based on pore formation in the cytoplasmic membrane of the target microorganism. This leads to a loss of small intracellular molecules and ions and a collapse of the proton motive force (Delves-Broughton, 2012; Tiwari et al., 2009).

They are supplied as dry cell-free powder and the food industry uses them to extend the shelf life of food and inhibit foodborne pathogens (Taylor, 2014; Elsser-Gravesen and Elsser-Gravesen, 2014). An important advantage between these undefined fermentates and other bacteriocins is that they are not purified by downstream processes and so can be simply labeled as "cultured milk" or "dextrose powder". Their active ingredients are not declared in some countries, including the United States, resulting in extremely friendly 
labeling when used in processed foods. However, the European Union decided not to adopt such polices and requires the labeling to declare the active ingredients (DelvesBroughton, 2012).

In nowadays Microgard range from DuPont and DuraFresh range from Kerry are the two commercially available fermentates. Alta and Perlac from Quest were two other fermentates that existed but are no longer available in the market. Even though the available research about the functionality of fermentates in foods is limited the industrial applications are wide (Elsser-Gravesen and Elsser-Gravesen, 2014).

Microgard is a fermented skimmed milk or dextrose with $P$. Shermanii or specific lactococci product. It is a potential inhibitor for Gram-negative bacteria such as Pseudomonas, Salmonella and Yersinia. Microgard ${ }^{T M} 100$ was proved to be effective in inhibiting Gram-negative organisms, yeasts, and molds in dairy products (Al-Zoreky et al., 1991). On the other and, when Microgard ${ }^{T M} 100$ and Microgard ${ }^{T M} 300$ were tested in an acidified chicken meat model stored at $22{ }^{\circ} \mathrm{C}$, there was no significant effect on aerobic mesophilic counts of E. coli and Brochothrix thermosphacta (Lemay et al., 2002).

Later, $1 \%$ of Microgard ${ }^{T M} 200$ and Microgard ${ }^{T M} 300$ solutions where applied to hamburgers. The results showed some initial reduction of $E$. coli $\mathrm{O} 157: \mathrm{H} 7$ and bacteriostatic effect against L. monocytogenes during refrigerated storage (Dave et al., 2003).

Also, the combination of nisin and Microgard ${ }^{T M}$ was tested in fresh salmon stored at $6{ }^{\circ} \mathrm{C}$. There was a reduction of the total aerobic count by $2 \log 10$ and a prolongation of shelf life of the salmon by 3 to 4 days (Zuckerman and Ben Avraham, 2002). Furthermore, certain combinations of Microgard ${ }^{T M} 300$ with nisin were effective in inhibiting $L$. innocua, in liquid cheese whey (von Staszewski and Jagus, 2008).

Toxicity tests were performed with Microgard ${ }^{T M} 200$ and no detrimental effects were observed, proving its GRAS status (Buard et al., 2003). In 2011, Durafresh was approved by the FDA, Food and Drug Administration, for its use in cottage cheese to control Listeria (Elsser-Gravesen and Elsser-Gravesen, 2014).

\subsection{Use of liquid smoke as antimicrobial}

The use smoke as a preservation method became common since the $1880 \mathrm{~s}$. The traditional method consists of generating natural wood smoke by controlled smoldering of wood in the absence or at reduced oxygen levels, forming a suspension of vapors, solid particles and liquid droplets. Later in the 1970s, concerns of the presence of carcinogenic benzopyrenes arisen and so liquid smoke emerged (Holley and Patel, 2005). Additionally, liquid smoke requires less time than traditional smoking and is more environmentally friendly 
while still giving the desired flavors and aromas to food (Lingbeck et al., 2014; Montazeri et al., 2013).

To produce liquid smoke, smoke from smoldering sawdust or wood chips is passed to a condensing tower where it is capture in water. Solutes with low solubility precipitate during holding times superior to 10 days and commercial liquid smoke is obtained from the solution after a filtration step to remove polycyclic aromatic hydrocarbons (PAH). At the end the liquid is aged for mellowness (Holley and Patel, 2005; Vitt et al., 2001; Lingbeck et al., 2014).

Compounds in wood smoke are consider as GRAS and have shown promise as natural antimicrobials. The temperature of smoke generation, the moisture content of the wood and the type of wood used influence the flavour and antimicrobial properties of liquid smoke produced. It can be produced from hickory, mesquite, rice hulls, coconut shells and pecan shells. In general, the wood is comprised of $25 \%$ hemicellulose, $50 \%$ cellulose and 25\% lignins (Holley and Patel, 2005).

Pyrolysis occurs in four different stages, water evaporation, decomposition of hemicelluloses, cellulose decomposition and final decomposition of lignins. Pyrolysis of hemicellulose and cellulose occurs between $180^{\circ} \mathrm{C}$ and $350^{\circ} \mathrm{C}$ and produces carboxylic acids and carbonyl compounds while lignins are pyrolyzed between $300{ }^{\circ} \mathrm{C}$ and $500{ }^{\circ} \mathrm{C}$ and generate phenols (Šimko, 2005; Lingbeck et al., 2014). The generated compounds are responsible for the antimicrobial activity of liquid smoke (Holley and Patel, 2005). PAH can also be produced during the pyrolysis of wood. Some occur naturally, and others result from incomplete burning. Since they are consider to be extremely toxic, the liquid smoke is filtrated to remove these compounds, as stated before (Lingbeck et al., 2014).

Pyrolysis of different woods generate different levels of phenols, carbonyls, organic acids and other components which will affect the liquid smoke antimicrobial properties (Lingbeck et al., 2014). These compounds belong to many different chemical classes: aldehydes; ketones; alcohols; acids; esters; furan and pyran derivatives; phenolic derivatives; hydrocarbons; nitrogen compounds. Among them, the phenolic fraction probably represents the most important. This portion is constituted mainly by phenol, 2methoxyphenol (guaiacol), 2,6-dimethoxyphenol (syringol) and their derivatives and by dihydroxybenzenes originated from the pyrolysis of lignin (Bortolomeazzi et al., 2007).

The concentration of phenols in liquid smoke is around $9.9-11.1 \mathrm{mg} / \mathrm{mL}$ (Ramakrishnan and Moeller, 2002). Phenols disturb the cytoplasmic membranes of bacteria and cause the intercellular fluids to leak (Davidson et al., 2013). Carbonyls have been reported in liquid smoke in amounts around 2.6 to $4.6 \%$ and their antimicrobial efficacy is due to the 133 different entaldehydes and ketones present in liquid smoke (Milly et al., 
2005). Carbonyls inhibit microbial growth by penetrating the cell wall and inactivating enzymes located in the cytoplasm and the cytoplasmic membrane (Lingbeck et al., 2014).

In this way, many studies were conducted to observe the susceptibility of major foodborne pathogens like L. monocytegenes, Staphylococcus, Gram-positive bacteria and Salmonella and E. coli, Gram-negative bacteria to liquid smoke in laboratory media and food systems.

To control the potential hazard of surface contamination of beef franks with L. monocytogenes, five different Red Arrow smoke products (CharSol-10, CharSol PN-9, AroSmoke P-50, CharDEx Hickory, CharOil Hickory) were evaluated for their antimicrobial activity in $0.5 \%$ and $0.25 \%(\mathrm{v} / \mathrm{v})$ smoke preparations against L. monocytogenes. Messina concluded that CharSol-10 liquid smoke exhibited an approximately $99.9 \%$ reduction in L. monocytogenes numbers even after $72 \mathrm{~h}$ of storage, being considered the most efficient natural antimicrobial by the author (Messina, 1988).

AM-3 Liquid smoke from the Mastertaste Inc. was sprayed on frankfurters formulated without sodium diacetate after peeling, and then inoculated with L. monocytogenes. It was observed that the levels of contamination on the treated frankfurters continued to decline until they were below detection level $\left(1 \mathrm{CFU} / 100 \mathrm{~cm}^{2}\right)$. The shelflife study lasted 140 days indicated that liquid smoke suppressed the growth of L. monocytogenes for up to 130 days (Martin et al., 2010).

Liquid smoke generated from pyrolysis of rice hulls showed bactericidal against $S$. Typhimurium in disk diffusion assay with concentrations ranging from $0.1 \%$ to $1 \%(\mathrm{v} / \mathrm{v})$. The minimal inhibitory concentration, MIC, determined by a broth dilution assay was of $0.822 \%(\mathrm{v} / \mathrm{v})$. The in situ antibacterial activity was also tested and the liquid smoke also enhanced survival of mice infected with a lethal dose of Salmonella, surviving twice as long (14 days) to mice that were not fed with liquid smoke (Kim et al., 2012).

Van Loo et al. 2012 determined MICs from eight commercial liquid smoke samples from three commercial manufactures against S. enteritidis, Staphylococcus aureus, and E. coli using a microdilution method. The MICs of the commercial liquid smokes ranged from 0.5 to $6.0 \%$ (v/v) for E. coli, 0.5 to $8.0 \%$ (v/v) for Salmonella, and 0.38 to $6 \%$ $(\mathrm{v} / \mathrm{v})$ for $S$. aureus. The results indicate that the liquid smoke samples tested in this study could serve as effective natural antimicrobials and that their inhibitory effects depended more on the solvents used for extraction than the wood source (Loo Van et al., 2012).

The efficacy of Zesti AM-5 a Kerry Ingredient and Flavours product on the shelflife of different cooked meats, pork ham and sausage was also tested. Results shown that Zesti AM-5 liquid smoke retards the outgrowth of L. monocytogenes, in pork ham. Additionally, Zesti AM-5 could delay this spoilage growth and even after 19 days the total bacterial count was still below $5 \log 10(\mathrm{CFU} / \mathrm{g})$. The main conclusion being, that 
the product can extend the shelf-life for more than 10 days acting as an efficient natural antimicrobial (Vercammen A et al.).

Even though the cases presented above are mainly done in meat, the same microorganisms can also be present in juices and dairy products (Tribst et al., 2009), hence the potential use of liquid smoke as an natural antimicrobial agent as substitute of potassium sorbate in fruit preparations.

\subsection{Use of antimicrobial from plant origin}

\subsubsection{Essential oils}

The use of essential oils (EO) isolated from spices and their plant sources in food preservation has become very popular. Although their first use dates back to prehistoric times, where the Egyptians used cinnamon, cumin and thyme for food preservations and also mummification (Delves-Broughton, 2012).

Essential oils can be obtained by steam or supercritical distillation, pressing or extraction by liquid or volatile solvents. The need to use pure solvents is essential, as is the requirement to carry out extraction under mild conditions utilizing solvents of low reactivity (López-Malo et al., 1995; Delves-Broughton, 2012).

It has been reported that antimicrobial activity of essential oils depends on the chemical structure of their components and on their concentration. The derivatives of phenol are the main antimicrobial compounds in essential oils; citral, eugenol, carvacrol, thymol, and vanillin are some of the active antimicrobial compounds from plant essential oils (Vigil et al., 2005). The mode of action of essential oils have been studied for some time but have not been completely clarified (Davidson et al., 2005). Some antimicrobial compounds in plants can interfere with the phospholipid bilayer of the cell membrane, disrupt the cell enzyme systems, compromise the genetic material of a bacterial cell, or form fatty acid hydroperoxidase by oxygenation of unsaturated fatty acids (Burt et al., 2007).

Fung et al. in 1977 suggested that the effect of phenolic compounds as antimicrobial agents is concentration dependent. At lower concentrations, they affected enzyme activity, especially of those enzymes associated with energy production. At greater concentrations phenols caused protein denaturation. The effect of phenolic antioxidants on microbial growth and toxin production could be the result of the ability of phenolic compounds of altering microbial cell permeability, permitting the loss of macromolecules from the interior. Also, they could interact with membrane proteins, causing a deformation in its structure and functionality (Fung et al., 1977). Conner and Beuchat in 1984 suggested 
that the antimicrobial activity of essential oils on yeasts could be due to a disturbance in several enzymatic systems involved in energy production and structural components synthesis. Once phenolic compounds crossed the cellular membrane, interactions with membrane enzymes and proteins would cause an opposite flow of protons, affecting cellular activity (Conner and Beuchart, 1984).

It is also thought that organic acids present in plant may also inhibit NADH oxidation, thus eliminating supplies of reducing agents to electron transport systems (Taylor, 2014). The undissociated portion of an acid molecule is primarily responsible for the antimicrobial activity dues its effectiveness at a given $\mathrm{pH}$ depends largely on the dissociation constant (pKa) (Hosein et al., 2011). Ricke defends that the organic acids interfere with membrane permeability. Short-chain organic acids interfere with energy metabolism by altering the structure of the cytoplasmic membrane through interaction with membrane proteins (Ricke, 2003).

Flavanoids, also have antimicrobial activity due to the ability of penetrating the cell membrane of bacteria causing membrane damage and changes in intracellular $\mathrm{pH}$, membrane potential and adenosine triphosphate synthesis. (Davidson et al., 2013)

Oils that have shown greatest activity against microorganisms are cloves, cinnamon, oregano, and thyme, and their primary components are eugenol, cinnamaldehyde, carvacrol, and thymol, respectively. Other essential oils or extracts from melissa, basil, bay, cilantro (coriander), citrus, cumin, dill, fingeroot, laurel, lemongrass, marjoram, nutmeg, rosemary, sage, savory, tea tree oil, vervain, and yerba mate have demonstrated moderate to high activity against selected microorganisms in some studies (Holley and Patel, 2005; Taylor, 2014; Davidson et al., 2013)

\subsubsection{Citrus extract}

Large amounts of citrus peel and seeds are the primary waste material originated from the production of fruit juices (Bocco et al., 1998). Citrus EOs contain on average 85 99\% volatile and $1-15 \%$ non-volatile components. The volatile ones are consider a mixture of monterpene (limonene) and sesquiterpene hydrocarbons and their oxygenated derivates (citral, ketones, acids, alcohols(linalool)) and esters) (see Table 2.1 ) (Moufida and Marzouk, 2003). Limonene, citral and linalool are the major components. Flavanoids are another important group of components that are present in the citrus extract. There are six classes of flavonoids: flavanones, flavonols, isoflavonoids, anthocyanins and flavans, which make up the non-volatile part of the oils (Bocco et al., 1998). Despite this, the components in EOs vary from season, ripeness and geographical region, which implicates variations in the ratios of the different components (Smith et al., 2001). Also, the 
composition of the blend of components in specific ratios determines not only the flavor but the possible antimicrobial effects of citrus oils (Fisher and Phillips, 2008).

Table 2.1: The most common volatile compounds found in citrus fruit (adapted from (Moufida and Marzouk, 2003))

\begin{tabular}{cccc}
\hline Volatile compounds & Sweet orange\% & Lemon\% & Bergamot\% \\
\hline Methanol & 0.37 & 0.20 & 0.35 \\
Isopropanol & 0.91 & 0.12 & 0.28 \\
$\alpha$-Pinene & 6.37 & 0.27 & 1.39 \\
Butylacetate & 0.00 & 1.47 & 4.97 \\
3-Heptanone & 0.00 & 0.34 & 0.94 \\
Limonene & 88.21 & 78.84 & 72.88 \\
Ocimene & 0.00 & 3.85 & 0.00 \\
Nonanol & 0.00 & 0.26 & 0.00 \\
Linalool & 0.02 & 0.02 & 10.23 \\
$\alpha$-Terpineol & 0.71 & 1.30 & 0.00 \\
Valencene & 0.00 & 3.34 & 0.00 \\
$\alpha$-Terpinene & 0.00 & 0.46 & 0.23 \\
$\beta$-lonone & 0.00 & 0.35 & 0.11 \\
$\beta$-Pinene & 0.00 & 0.02 & 0.14 \\
p-Cymene & 2.37 & 1.75 & 5.62 \\
Citral & 3.00 & 0.10 & 0.70 \\
\hline
\end{tabular}

In 2005 Citrus limonum was found to be effective against four strains of E. coli with MIC values of $2.5 \mathrm{~mL} / 100 \mathrm{~mL}$ in Brain Heart Infusion Broth at $37{ }^{\circ} \mathrm{C}$ (Moreira et al., 2005), however these results were corroborated by $\mathrm{Si}$ et al, where the study showed that there was a less than $50 \%$ inhibition against $E$. coli from lemon oil and citral (major component) (Si et al., 2006).

Lemon, sweet orange and bergamot and their components, linalool and citral were found to have antimicrobial effects against Campylobacter jejuni, E. coli O157, L. monocytogenes and Bacillus cereus. In vitro MICs values were determined and only bergamot ( 1 to $0.125 \%$ (V/V)), linalool (0.06 to $0.125 \%$ (V/V)) and citral $(0.03$ to $0.06 \%(\mathrm{~V} / \mathrm{V})$ ) had concentrations that would be acceptable to food application (Fisher and Phillips, 2006)

Regarding antifungal activity, citral has been recognized as an active compound in citrus fruits. One study tested the antifungal activity of the following citrus oils: Citrus sinensis, Citrus aurantium, Citrus deliciosa, Citrus paradises and C. limon and found their effective doses to be $2180,1015.4,713.3$, 910.3 , 1056.4 ppm on Penicillium digitatum, correspondingly (Caccioni et al., 1998). Schelz et al. proved that orange oil also inhibits the growth of Saccharomyces cerevisiae at 4 log cells, with an high MIC value of $2.8 \mathrm{mg} / \mathrm{mL}$ (Schelz et al., 2006). $\mathrm{pH}$ and water activity influences were also 
tested in the possible application of citral as an antimicrobial on Aspergillus flavus. The results show $\mathrm{pH}$ did not effect the MIC yet water activity did. When the water activity was $0.99,1800 \mathrm{ppm}$ were needed to inhibit the growth and 1400-1600 ppm for water activity of 0.95 (López-Malo et al., 2005).

Notwithstanding, it was proven that the intensity of the oils decrease over time due to the most volatile components evaporating first (Saiyasombati and Kasting, 2003). Due to Citral high volatilisation rate, it was show that its antimicrobial activity occurs rapidly in the first $3 \mathrm{~h}$ of contact and then diminishes just as rapidly hereon (Inouye et al., 2003).

\subsubsection{Vanillin}

Vanillin, 4-hydroxyl-3-methoxybenzaldehyde, a phenolic compound, is the main component of vanilla beans of the tropical Vanilla orchid. It is recognized as GRAS product being widely used as a flavoring compound and for its antifungal and bacteriostatic properties (Rupasinghe et al., 2006; Delves-Broughton, 2012; Fitzgerald et al., 2004). Natural vanillin is obtained by alcohol aqueous solutions or by supercritical $\mathrm{CO}_{2}$ (carbon dioxide) extraction from cures vanilla beans (López-Malo et al., 1995; Vigil et al., 2005).

Earlier on, vanillin was reported to be most effective against mold and non-lactic Gram- positive bacteria (Jay and Rives, 1984). In 1995 a study made by López-Malo et al. concentrations ranging from 3 to $7 \mathrm{Mm}$ of vanillin inhibited five species of Aspergillus in several fruit-based agars during two months (López-Malo et al., 1995). In another study, tests made in both laboratory media and apple purée reveals complete inhibition of the growth of three yeast species (S. cerevisiae, Zygosaccharomyces rouxii, Debaryomyces hansenii and Zygosaccharomyces bailii) when using $200 \mu \mathrm{g} / \mathrm{mL}$ of vanillin for 40 days of storage at $27{ }^{\circ} \mathrm{C}$. However, it was ineffective in banana puree, thought to be due to the high lipid/protein levels found in bananas (Cerrutti and Alzamora, 1996).

Vanillin has also shown to be effective against $S$. cerevisiae and Candida parapsilosis in laboratory media with MICs of 17 and $9 \mathrm{mM}$ correspondingly. In the same study, the vanillin antimicrobial properties were studied in peach-flavoured soft drinks and fruit juices. The results vary depending on the storage temperatures $\left(8-25^{\circ} \mathrm{C}\right)$. Vanillin is more effective at concentrations of $20 \mathrm{mM}$ against $S$. cerevisiae and $10 \mathrm{mM}$ against $C$. parapsilosis. In both yeast strains that were inoculated, vanillin was able to completely inhibit them for eight week storage at $25{ }^{\circ} \mathrm{C}$, at a level of around $104(\mathrm{CFU}) / \mathrm{mL}$ (Fitzgerald et al., 2004).

Vasantha Rupasinghe et al. 2006, studied the antimicrobial effect of vanillin against four pathogenic organisms: E. coli, Pseudomonas aeruginosa, Enterobacter aerogenes, and S. enterica subsp. enterica serovar Newport and four spoilage organisms: Candida 
albicans, Lactobacillus casei, Penicillum expansum, and S. cerevisiae in fresh-cut products. MIC of vanillin vary between 6 and $18 \mathrm{mM}$ depending on the microorganisms. When associated with anti-browning dipping solution vanillin inhibited the total aerobic microbial growth by $37 \%$ and $66 \%$ in the two commercially available fresh-cut apples, during storage at $4{ }^{\circ} \mathrm{C}$ for 19 days (Rupasinghe et al., 2006).

Vanillin was also studied as a natural antimicrobial on strawberry juice. Vanillin, in concentration of 1.5 and $5 \mathrm{mg} / \mathrm{mL}$, was effective in reducing the native microflora on the juice, extending the shelf-life time of the product. In this same study, the juice was inoculated with $E$. coli $\mathrm{O} 157: \mathrm{H} 7$ (105 CFU/mL) before being treated with vanillin, where the inoculated $E$. coli levels were reduced substantially (Tomadoni et al., 2016).

\subsubsection{Hydrosols}

Hydrosols are a by-product obtained by steam distillation of plant material. Commonly, plants are distilled to obtain an essential oil, however, some plants are processed to produce hydrosols (Inouye et al., 2009; Acheampong et al., 2015). The hot steam, breaks the structure of plant cells, releasing the volatile molecules from the cellulosic substrate and so the essential oils are in direct contact with the steam. Upon condensation, some essential oil compounds, the ones more water-soluble oxygenated polar compounds like phenolic compounds (catechol, protocatechuic acid, caffeic acid, chlorogenic acid, catechin, cyanidin), methylated flavones (tangeretin), flavonols (morin, maringenin, and hesperitin), glucosides, glycosides, alkaloids and lactones, dissolve in the aqueous phase and form the so-called hydrosol (Bohra et al., 1994; Lis-Balchin et al., 2003; Hay et al., 2015). In this way, they are consider to be a complex mixtures containing traces of essential oils and other water-soluble compounds (Inouye et al., 2009). Compared to the essential oils, little work on antimicrobial and antifungal activity of hydrosols has been reported (Acheampong et al., 2015; Inouye et al., 2009).

Hydrosols are scented product, and its composition and antimicrobial effects depend on plant species and regional conditions (Sağdiç and Özcan, 2002). However, they have been used as a beverage for a long time in Turkey (Tajkarimi et al., 2010). They are also used in the cosmetic and medical field since they are very easy and inexpensive to produce. Additionally, they are not consider a health hazard to human beings as is some cases of essential oils (Inouye et al., 2009; Lis-Balchin et al., 2003; Tornuk et al., 2011).The antimicrobial activities of hydrosols might be originated from their monoterpenic essential oil compounds and phenolic compounds (Tornuk et al., 2011).

The in vitro antibacterial activity of the hydrosols of sixteen spices were tested on fifteen bacteria (Bacillus amyloliquefaciens ATCC 23842, Bacillus brevis FMC 3, B. cereus 
FMC 19, Bacillus subtilis var. niger ATCC 10, E. aerogenes CCM 2531, E. coli ATCC 25922, E. coli O157:H7 ATCC 33150, Klebsiella pneumoniae FMC 5, Proteus vulgaris FMC 1, S. enteritidis, Salmonella gallinarum, S. typhimurium, S. aureus ATCC 2392, S. aureus ATCC 28213, Yersinia enterocolitica ATCC 1501) using an agar well-difusion method. Only oregano and summer savory hydrossols were effective against all bacteria during incubation. Anise, cumin and black thyme hydrosols were active against some bacteria, but not all (Sağdiç and Özcan, 2002). Musa Özcan also analyzed the inhibitory effects of the same 16 spice hydrossols on the mycelial growth of Aspergillus parasiticus. Hydrosols of cumin, fennel, mint, oregano, pickling herb, savoury, and thyme were $100 \%$ effective in controlling the fungi growth during 8 days of incubation whereas sumac hydrosol was ineffective (Özcan, 2005). Additionally, Özcan and Boyraz tested rosemary, cumin, sater, basil and pickling herb hydrosols agains other fungi (Rhizoctonia solina, Fusarium oxyporum, Botrytis cinerea and Alternaria citri). The author concludes that sater hydrosol showed the highest fungistatic activity against all the pathogens, and pickling herb and cumin hydrosols followed. Fungistatic activities of rosemary and basil hydrosols were lower than the other hydrosols tested (Boyraz and Özcan, 2005).

A.I. Al-Turki, demonstrated, in vitro, that thyme, peppermint, sage, black pepper and garlic hydrosols had antibacterial activities against $B$. subtilis and S. enteritidis. From the hydrosols tested, garlic had the stronger antibacterial activity and the combination of thyme, mint and sage (1:1:1 mixing ratio) had slightly higher antibacterial activity when compared with single plant hydrosols (Al-Turki, 2007). In another study, Inouye et al. 2009 studied the antifugal activity in vitro of 43 hydrosols against $C$. albicans in its yeast and filamentous form. Monarda, santolina and clove hydrossols were the only ones who inhibited the growth of the yeast form. The results also show that lemongrass, lemon verbena, tea tree lemon, rose geranium, neroli, kuromoji, palmarosa, Roman chamomile, monarda, clove, santoline and dry's chamomile hydrossols reduced the filamentous growth up to $80 \%$ even after 5-fold dilution (Inouye et al., 2009). Furthermore, in another article, $100 \%$ growth inhibition was demonstrated at $15 \%$ hydrosol concentration of cardamom and thyme against $E$. coli, cardamom and cinnamon against $S$. aureus and cardamom, thyme and cinnamon against Staphylococcus typhil (Hussien et al., 2011).

In more recent years, the antimicrobial potency of hydrosols made from leaves and fruit peels (leaves of Cymbopogon nardus, Chromolaena odorata, Ocimum gratissimum, Cymbopogon citratus, and fruit peels of Citrus sinensis and Citrus aurantifolia) were tested against E. coli, S. aureus, C. albicans, B. subtilis and Enterococcus faecalis was analysed using agar well-diffusion method. The results show that only the hydrosol from fresh fruit peels of Citrus aurantifolia exhibited antimicrobial activity against all the tested organisms possibly duo to the higher content of phenols and flavonoids in this hydrosol 
(Acheampong et al., 2015). In another study, the antimicrobial activity of thyme and rosemary hydrosols were tested though a diffusion method against 3 bacteria (E. coli, $P$. aeruginosa and $S$. aureus) and 2 fungi (C. albicans and Aspergillus niger). Rosemary hydrosols did not present any inhibitory activity against any bacteria or fungi tested up to concentrations of $500 \mu \mathrm{L} / \mathrm{mL}$. Moreover, thyme hydrosols showed MIC of $250 \mu \mathrm{L} / \mathrm{mL}$ against $P$. aeruginosa, $S$. aureus and the 2 fungi. Though this concentration is very high for a preservative, it could possibly be used as an active ingredient to promote product conservation (Hay et al., 2015).

In situ studies using hydrossols were also made. In 2003 hydrosols originated from Pelargonium (Geraniaceae) leaves, at a concentration of $1000 \mathrm{ppm}$, were assessed for their antimicrobial activity in a model food system (broccoli soup). The soup was inoculated with E. aerogenes (at $105 \mathrm{CFU} / \mathrm{g}$ ) and S. aureus (at $104 \mathrm{CFU} / \mathrm{g}$ ). The results strongly suggest that the hydrosol had no potential as antibacterial agent in food since their use potentiated bacterial growth in this study (Lis-Balchin et al., 2003). Some years later, the antimicrobial properties against S. Typhimurium and E. coli $\mathrm{O} 157: \mathrm{H} 7$ inoculated in apple and carrots of hydrosols (thyme, black cumin, sage, rosemary and bay leaf) were investigated by Tornuk et al. 2011. The work shown that plant hydrosols, especially thyme hydrosol, could be used as a convenient sanitizing agent during the washing of fresh-cut fruits and vegetables since it showed the highest antibacterial effect on both bacteria (Al-Turki, 2007).

\subsection{Challenges}

One of the main objectives of the food industry is to substitute chemically synthesized preservatives for natural antimicrobial, however this revealed to be a difficult task.

The addition of natural antimicrobials usually increases the cost of the final product depending on their production method and the raw material they are originated from (Taylor, 2014). Also, when the antimicrobials are added to the final product they should not affect their natural flavor and color, however in the case of liquid smoke and hydrosols, the case may not be possible to achieve (Montazeri et al., 2013). Additionally, most of the studies presented on the section above were done in vitro, and the antimicrobial activity of this substances when applied in food matrices may change (Lis-Balchin et al., 2003). During food processing the natural antimicrobial may not be stable since their activity may vary due to changes in temperature, $\mathrm{pH}$ and other environmental properties (Acheampong et al., 2015; Fuglsang et al., 1995). Because of this, the stability of the bioactive compounds should be considered during the process of food. Since the objec- 
tive of the present work is to study the natural antimicrobials in fruit formulations, it is important to know if the antimicrobials are stable during a pasteurization step to determine if the natural preservatives should be added before or after. Furthermore, since the antimicrobial activity should be maintain during the product life-cycle, the stability during storage is also an important factor (Ramakrishnan and Moeller, 2002). Nevertheless, the final application of the fruit preparation is to incorporate them in yogurt, so an important issue may emerge since the tested natural antimicrobials may have a negative interference with the lactic cultures present in yogurt (Hui, 2007). 


\section{Chapter 3}

\section{In vitro assessment of the antifungal activity of the natural antimicrobials}

\subsection{Introduction}

Spoilage indicates changes in the condition of food that makes it less appealing at the time of consumption. The spoilage problems can be divided into physical spoilage (moisture loss, staling), chemical spoilage (rancidity) and microbiological spoilage (yeast, mold and bacterial growth). Also, spoilage can be influenced by inter-related factors, specifically storage temperature, relative humidity, level of preservatives, $\mathrm{pH}$, packaging material and gaseous environment surrounding the product, the moisture content and finally water activity (aw) (Smith et al., 2004). When it comes to spoilage, microbiological spoilage is often the major factor limiting the self life of food products being mostly influenced by its water activity. Products with high water activity (aw), between 0.94 to 0.99 almost all bacteria, yeast and molds are capable of growing (Seiler, 1999).

Following Legan and Voysey ideals, yeast problems can be subdivided into two types, visible growth of yeasts on the surface of the products (white or pink patches) and, fermentative spoilage manifested by alcoholic, esteric, or other odors and/or visible evidence of gas production (ex: gas bubbles in jams). The most common osmotolerant yeast that causes spoilage of high sugar coatings and fillings such as jam, marzipan, and mincemeat, is Z. rouxii (Legan and Voysey, 1991). Candida, Pichia, Rhodotorula, Torulopsis, Saccharomyces, Zysossaccharomyces, Hansenula, and Trichosporon genera have also been associated with juice spoilage (Tribst et al., 2009).

Many molds are capable of growing at aw values of 0.8 while a few xerophilic molds are capable of growth at aw values as low as 0.65 (Legan and Voysey, 1991). They can produce gas, change the odor and form mycelial mats on the juice surface. Com- 
monly found genera, such as Aspergillus and Penicillium can be found in fruits (103-105 $\mathrm{CFU} / \mathrm{mL}$ ), especially when good manufacturing practices are not correctly applied (Tribst et al., 2009).

From the primitive times fungi have been present in food products causing them premature spoilage. Additionally, secondary metabolites toxic to the human organism can be produced and an important issue regarding food safety emerges (Dijksterhuis et al., 2013; Pitt and Hocking, 2009). To assure this, several food-preservation techniques have been utilized to control microorganisms in foods, including chilling, freezing, water activity reduction, nutrient restriction, acidification, modified atmosphere packaging (MAP), fermentation, and nonthermal physical treatments or the addition of synthetic antimicrobials (Davidson et al., 2013). The use of synthetic preservatives raised concerns over negative health issues which motivated the scientific community to substitute these chemically synthesized preservatives for natural antimicrobials products (Sofos and Geornaras, 2010).

Preparations produced by FRULACT are prone to be contaminated by fungus due to their low $\mathrm{pH}$, high content in sugars and high aw. To ensure microbiological safety these preparations are subjected to a suitable heat treatment, pasteurization, in a closed process and packaging line. In addition to this, if the client demands so, potassium sorbate is added, a known chemically synthesized fungi inhibitor (Pitt and Hocking, 2009).

To achieve the main objective of the project which is to substitute potassium sorbate, the antifungal activity of the antimicrobials has to be tested. Hence, in this chapter the in vitro antifungal activity of some natural antimicrobials was tested against the most occurring fungi identified in a previous work done at FRULACT (dos Santos, 2016). Microorganisms which were isolated from the most contaminated raw materials and several areas of the Tortosendo factory. The screening of several antimicrobial agents is essential in this initial stages of the project in order to select the most promising ones and test them in fruit preparations and in dosed yogurt.

\subsection{Materials and Methods}

\subsubsection{Maintenance of the isolated microorganisms}

The microorganisms tested were: Aspergillus sp., Candida santamarie, Chaetomoium sp., Cladosporium sp., Cryptococcus sp., Epicoccum nigrum, Mucor piriformis, Penicillium sp., Phoma sp. and Peyronellaea glomerata, Pichia anomala. and are displayed in Table A.1 and Table A.2 present in the Appendix A. 
Every two week the pure cultures were renovated in Patato Dextrose Agar (PDA) plates. The plates were incubated at $25 \pm 1{ }^{\circ} \mathrm{C}$ during $5 \pm 2$ days and then stored at $4 \pm 1$ ${ }^{\circ} \mathrm{C}$.

\subsubsection{Antimicrobials tested}

The natural antimicrobials tested for their antifungal activity are present in Table 3.1.

Table 3.1: Natural antimicrobials studied, their physical state and respective supplier. The suppliers are not discriminated due to confidentiality clauses

\begin{tabular}{ccc}
\hline Antimicrobial & Physical form & Supplier \\
\hline Lactoperoxidase & powder & $\mathrm{A}$ \\
Olive hydrossol & aqueous & $\mathrm{B}$ \\
Vanillin & powder & $\mathrm{C}$ \\
Smoke aroma 1 & aqueous & $\mathrm{D}$ \\
Smoke aroma 2 & aqueous & $\mathrm{D}$ \\
Organic citrus extract & aqueous & $\mathrm{E}$ \\
Citrus extract & aqueous & $\mathrm{E}$ \\
Cultured corn syrup & powder & $\mathrm{D}$ \\
\hline
\end{tabular}

\subsubsection{MIC determination}

The determination of the MIC values was done using the poisoned growing media technique (de los Santos G de Paredes and Romero Muñoz, 1999). The first step is to test the solubility of the antimicrobials in PDA. For the compounds that presented themselves in a powder form, stock solution of $10 \%(\mathrm{w} / \mathrm{V})$ in distilled water were prepared. In the case of vanillin, not soluble in water, the stock solution was done in $35 \%(\mathrm{~V} / \mathrm{V})$ ethanol.

Afterwords, PDA plates were prepared. After sterilizing the PDA medium, when it reached $55{ }^{\circ} \mathrm{C}$ the antimicrobials/stock solutions were added to obtain concentrations of $0.05 \% \quad 0.06 \% \quad 0.07 \% \quad 0.08 \% \quad 0.09 \% \quad 0.1 \%$ and $0.5 \%$ (w/V). After the addition of antimicrobials, agar solutions were poured into $90 \mathrm{~mm}$ diameter sterile Petri plates and allowed to solidify. The Petri plates were then inoculated with approximately $5 \times 5 \mathrm{~mm}$ plugs from the pure cultures in storage when testing the filamentous fungus. In the case of yeasts, scratches of biomass were used. The plates were incubated at $25 \pm 1{ }^{\circ} \mathrm{C}$ during 7 days and the growth was recorded at day 3,5 and 7 of incubation. A negative control, PDA plates without any antimicrobials, were prepared for comparison with the effective samples. Another negative control, PDA plates without any antimicrobials with $35 \%$ (V/V) 
ethanol were prepared for comparison with the vanillin samples. MIC values were determined as the lowest concentration at which each microorganism was total inhibit by the antimicrobials after the 7 days of incubation when simultaneously there was growth on the control plates. The Mycelia Growth Inhibition (MGI) was calculated by comparing the diameter of the control plates with the ones with the antimicrobials using the following equation:

$$
M G I \%=\frac{d_{c}-d_{s}}{d_{c}} \times 100 \%
$$

Where, $\mathrm{d}_{c}$ represents the average diameter of the colony in the control PDA plates and $\mathrm{d}_{s}$ is the average diameter of the colony in PDA plates containing tested antifungal agent (Pandey et al., 1981; Balouiri et al., 2016).

\subsection{Results and discussion}

As a first note the concentrations tested of the different antimicrobials were selected having in mind information given by the different suppliers.

When observing the results, presented in Table 3.2 and Table 3.3, the only natural antimicrobial which was $100 \%$ effective against all the tested microorganisms was the natural vanillin. The citrus extract showed some positive results, however it did not show the same efficacy as the natural extracted vanillin. The rest of the natural antimicrobials showed little antifungal activity.

Table 3.2: Antifungal activity of the natural antimicrobials tested on yeasts after 7 days incubation at $25^{\circ} \mathrm{C}$. MIC represents the minimal inhibitory concentration of each natural antimicrobial in (w/V)\% . RG represents the concentration at which there is a retarded growth of the colony when compared to the control in (w/V)\% . NA represents the compounds that did not show any antifungal activity against the tested microorganisms even at maximum concentrations of $0.5 \%(\mathrm{~m} / \mathrm{V})$

\begin{tabular}{ccccc}
\hline Natural Antimicrobial & Cryptococus sp. & P. anomala & C. Santamariea & Pichia sp. \\
\hline Lactoperoxidase & NA & RG- 0.1\% & NA & NA \\
Vanillin & MIC- $0.09 \%$ & MIC- $0.5 \%$ & MIC- $0.1 \%$ & MIC- $0.1 \%$ \\
Smoke aroma 1 & RG- 0.05\% & RG- 0.5\% & RG-0.08\% & RG- $0.05 \%$ \\
Smoke aroma 2 & NA & NA & NA & NA \\
Organic citrus extract & NG & NA & NA & NA \\
Citrus extract & NA & RG- $0.08 \%$ & RG- $0.1 \%$ & RG- $0.05 \%$ \\
Cultured corn syrup & NA & NA & NA & NA \\
\hline
\end{tabular}




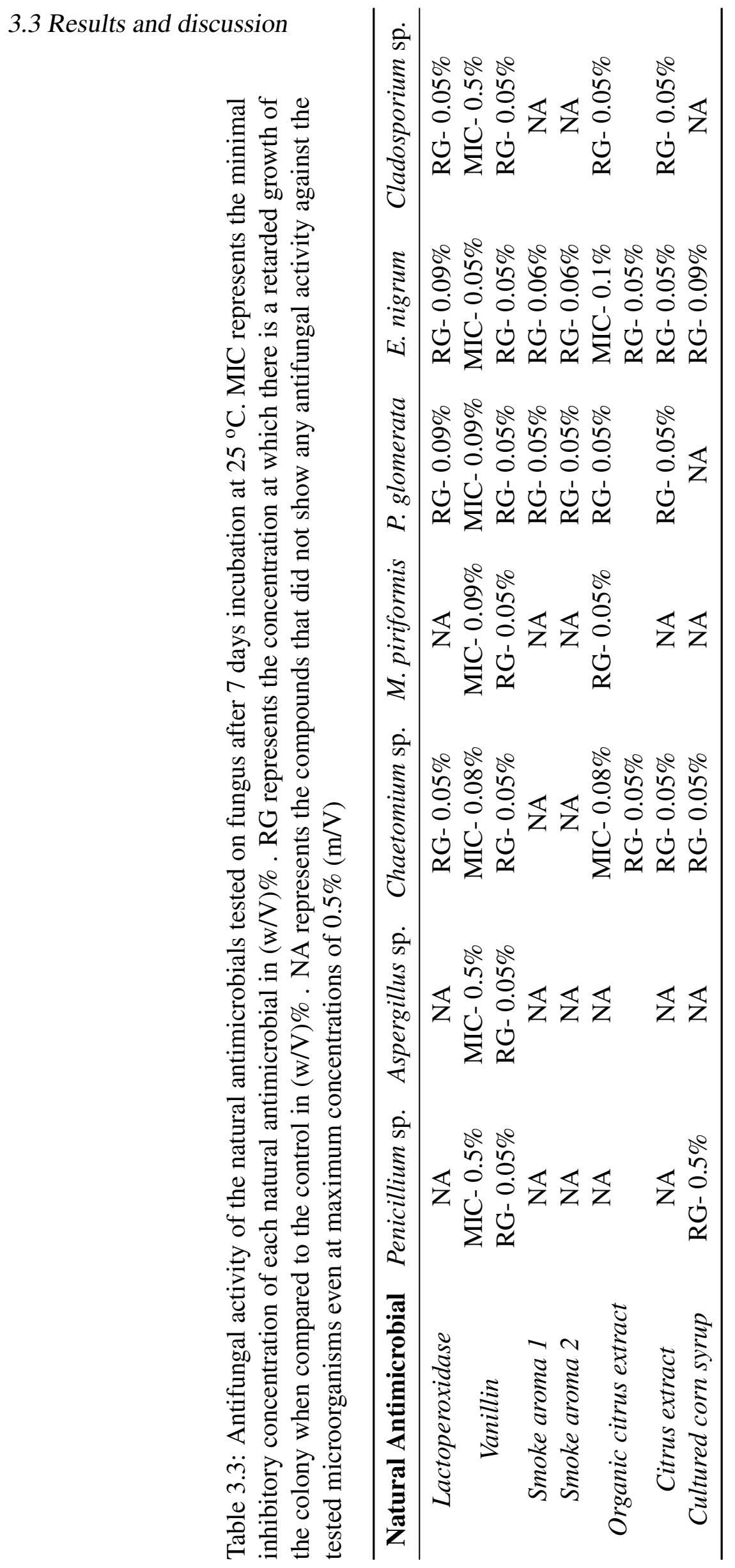


The olive hydrossol has shown to be insoluble in water and in a maximum concentration of $70 \%(\mathrm{~V} / \mathrm{V}$ ) of ethanol (Figure 3.1), because of this, it was not possible to test the antifungal activity of this natural antimicrobial in vitro and further tests with this compound where aborted. An hydrossol is consider to be a complex mixture containing traces of essential oils and other water-soluble compounds (Inouye et al., 2009) which contradicts the observed insolubility in water and ethanol. This hydrophobic nature could possibly be overcome with the use of emulsifiers such as Tween 20 or 80 or in combination with acetone, polyethylene glycol (Burt and Reinders, 2003; Fisher and Phillips, 2008), regardless of this fact, the final use of the compound would be in fruit preparations ergo his hydrophobicity would be a problem in future work.

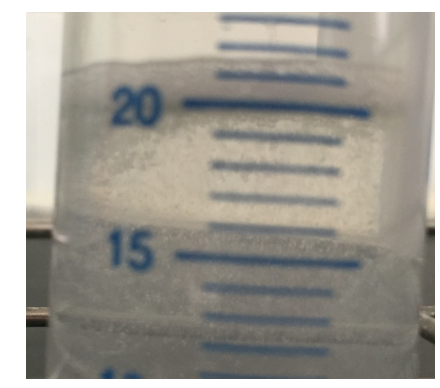

Figure 3.1: Micelles formation observed in $70 \%(\mathrm{~V} / \mathrm{V})$ ethanol with a concentration of $1 \%(\mathrm{w} / \mathrm{V})$ olive hydrossol

Also the values obtained of RG are important since they show when the antimicrobial start to inhibit the growth of the respective microorganism, however only MIC values are relevant to FRULACT and are important to ensure food safety.

It is important to refer that the commercial lactoperoxidase tested is in fact a mixture of the enzyme lactoperoxidase, glucose, glucose oxidase, whey,lactose and casein that optimize antimicrobial activity since, as stated in the previous section, the enzyme does not act on is own but interacting with other ions and molecules Chapter 2. The lactoperoxidase system did not show total inhibition of the growth on the tested microorganisms exhibiting just a slight regression in the growth of few microorganisms which is contradictory to the reviewed literature (Jacob et al., 2000; Dufour, 2003; Elotmani and Assobhei, 2004; Welk et al., 2009; Ahariz and Courtois, 2010; Taylor and Lathrop, 2015). Lactoperoxidase is stable up to $70{ }^{\circ} \mathrm{C}$ and in a wide range of $\mathrm{pH}$ from 4 till 10 being optimal between pH 5 and 6 (Kussendrager and van Hooijdonk, 2000), the main hypothesis to justify this lack of activity is that the method used is not ideal when dealing with enzymatic activity since the rigidity of the agar plates limits the mobility of the enzyme that it would eventually have in solution. For example, Jacob et al. studied the antifungal activity of lactopeoxidase in solution using macrobroth dilution and obtained MIC of $0.5 \%$ 
(w/V) on A. niger, Pencillium chrysogeum and A. flavus (Jacob et al., 2000). In 2003, Dufour et al. effectively tested the inhibitory potential of the enzyme using a microtites plate growth assay against 5 bacteria (Dufour, 2003). Also, lactoperoxidase showed a high fungicidal effectiveness in a nutrient broth when tested against $C$. albicans following the European norm EN 1275, which further proves the initial premise (Welk et al., 2009). Furthermore, the determination of the antimicrobial activity using the broth microdilution method is the fastest and most efficient screening method for MIC determination once different methods to determine MIC were compared (Klančnik et al., 2010).

However, in 2014 Taylor et al. tested the same lactoperoxidase-system and MIC values of $0.25 \%(\mathrm{w} / \mathrm{V})$ were obtained on Salmonella, E.coli and L. monytogenes. Even though, the study regarded the bacterial efficacy of lactoperoxidade, the study tested the antimicrobials in milk and cheese agar and not just PDA as done in the current project. It is well known that the activity of the enzyme is dependent upon the presence of $\mathrm{H}_{2} \mathrm{O}_{2}$ and either thiocyanate or a halide. In addition to lactoperoxidase, the antimicrobial tested also contained glucose and glucose oxidase, which utilizes glucose and oxygen to produce $\mathrm{H}_{2} \mathrm{O}_{2}$. The authors defend that the milk agar supported the action of the lactoperoxidase by contributing with thiocyanate (present in milk), in addition to the $\mathrm{H}_{2} \mathrm{O}_{2}$ produced by the glucose oxidase for antimicrobial activity. Since the PDA lacks this extra source of thiocynate the results obtained may be justified (Taylor and Lathrop, 2015).

The naturally extracted vanillin was the only natural antimicrobial that could inhibit by $100 \%$ the growth of every microorganism tested in a concentration of $0.5 \%(\mathrm{w} / \mathrm{V})$ including the most resistant species like Penicillium sp. and Aspergillus sp.. The MIC obtained is bigger than the one obtained by López-Malo et al. of $0.2 \%$ (w/V) against Aspergillus sp. (López-Malo et al., 1995). However, the one tested is naturally extract and not chemically synthesized which could have influenced the results. On Figure 3.2 it can be observed total inhibition effect of vanillin in Penicillium sp..

Vanillin's $99 \%$ purity probably indicates that it was more bio-available than the active molecules in the other antimicrobials tested, which are complex mixtures, thus having a higher antimicrobial activity. Since the tested antimicrobial has a higher purity, another important thing to have in mind is the price, when substituting potassium sorbate by a naturally extracted compound the price of the final product will increase. Notwithstanding, this matter will be addressed in the next chapter.

Both tested liquid smoke are produced by the same company and the main difference between them is the concentration, smoke aroma 2 is more concentrated than smoke aroma 1 (phenol level lower than $0.100 \mathrm{mg} / \mathrm{mL}$ ). Other information such as the type of sawdust originated from or its exact composition is not disclosed by the supplier. Therefore results should indicate that smoke aroma 2 has a higher antifungal activity since the 


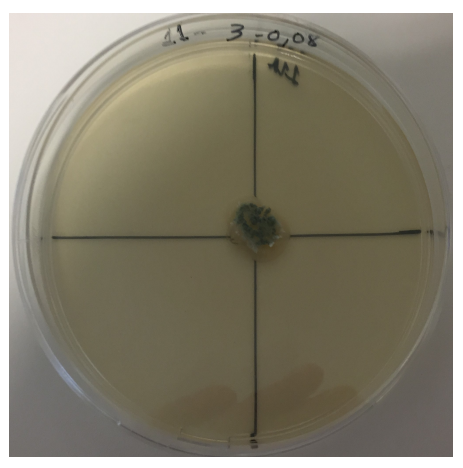

(a) Mycelial growth inhibition of Penicillium sp. by $0.08 \%(\mathrm{w} / \mathrm{V})$ of vanillin;

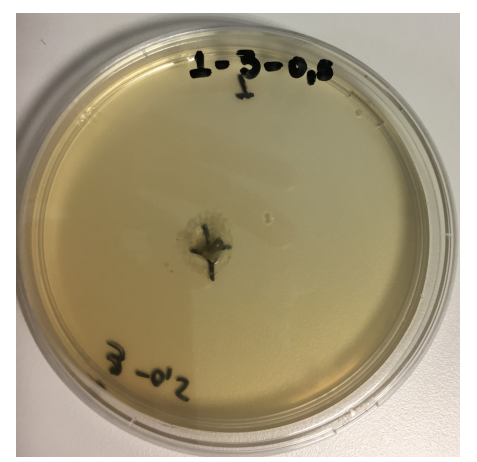

(b) $100 \%$ growth inhibition of Penicillium sp. by $0.5 \%$ $(\mathrm{w} / \mathrm{V})$ of vanillin;

Figure 3.2: Growth inhibition of Penicillium sp. at different concentrations of vanillin after 7 days incubation at $25^{\circ} \mathrm{C}$

phenol content is one of the main components responsible for antimicrobial efficiency (Bortolomeazzi et al., 2007). This predicament is not fulfilled since there is no antifungal activity in the tested yeasts (Table A.2) and little mycelial growth inhibition when analyzing the results obtained in fungus (Table A.1). When comparing inhibition both of them only inhibited the growth of $P$. glomerata and E. nigrum at the same concentrations correspondingly of $0.05 \%(\mathrm{w} / \mathrm{V})$ and $0.06 \%(\mathrm{w} / \mathrm{V})$. However, MGI was of $30 \%$ when dealing with smoke aroma 1 and $15 \%$ with smoke aroma 2 in the case of P. glomerata and in $E$. nigrum the value was the same, approximately $30 \%$. These low antifungal activities were not expected since the tested antimicrobials are commercially available, used industrially and have a wide range of applications (meat, poultry, fish, seafood, fruits and dairy products). Even so, positive results can be found in literature (Messina, 1988; Milly et al., 2005; Kim et al., 2012; Loo Van et al., 2012).

The majority of the in vitro studies is done in bacteria, though Milly et. al determine MIC values of commercially available brands on A. niger and $S$. cerevisiae and the values range from $1.5 \%$ to $9 \%$ concluding that the least effective smoke aroma had low phenols and low carbonyls which could reduce the antimicrobial activity (Milly et al., 2005). The range of concentrations tested in the current project is small when compared to values obtained of MIC by this author which could explain the lack of activity obtained. However the pungent flavor of the smoke aromas had been tested in preliminary work done at FRULACT, concluding so that above $0.1 \%(\mathrm{w} / \mathrm{V})$ the taste of the fruit preparations is not pleasant to most of the tested subjects. Due to this problematic, concentrations above this limit were not tested since the flavor would be a problem in the future. Another issue is the phenol content, it is know that most of the smoke aromas available have a concentration 
of phenols around $9.9-11.1 \mathrm{mg} / \mathrm{mL}$, a 100 times higher value than the one in smoke aroma 2 of $0.1 \mathrm{mg} / \mathrm{mL}$ which can again explain the lack of antifungal activity obtained (Ramakrishnan and Moeller, 2002).

When comparing the results of the tested citrus extract, the organic one has a stronger antifungal activity. Even though they were both produced from the same manufacturer, information about the exact composition and manufacturing process was not disclosed. Citrus extract could only inhibit the growth of the most sensible species like Chaetomium sp. in $83 \%$ E. nigrum in $70 \%$, P. glomerata in $37 \%$ and Cladosporium sp. in $55 \%$. This lack of antifungal activity could be explained by the rapid evaporation of the volatile compound that are know for their antimicrobial activity like citral (Inouye et al., 2003). Despite this, the organic citrus extract showed much more potential as a natural antimicrobial and even though it could not total inhibit the growth of the most resistant species, Penicillium sp. colonies showed signs of stress, changing its conformation as it can be seen in Figure 3.3. Further, information given by the supplier suggests no volatility of this antimicrobial which could explain these positive results when comparing to the other citrus extract.

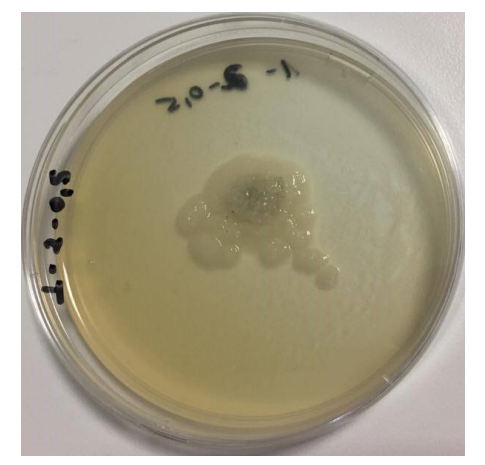

Figure 3.3: Mycelial growth inhibition of Penicillium sp. by $0.5 \%(\mathrm{w} / \mathrm{V})$ of organic citrus extract;

The supplier tested the organic citrus extract against bacteria and some fungi and found values of MIC was of 39 ppm against Candida zeylanoides and Candida lipolytica, and although this genera of Candida was not tested in the current project, MIC values against the Candida sp. could not be obtained. MIC values on A. flavus, Penicillium furcalum and Mucor sp. were also given by the supplier being respectively 313, 156 and $156 \mathrm{ppm}$. Again, the tested microrganisms do not have the same genera, however these values could not be match in the project and no MIC value could be obtained on the tested Aspergillus sp., Penicillium sp. and M. piriformis. One can argue that the method and the 
environmental conditions (temperature, $\mathrm{pH}$, water activity) of obtaining these values may differ and be the cause for variations in the results.

In literature, MIC values ranging from 4.67 to $25 \mathrm{mg} / \mathrm{mL}$ were obtained when different citrus extracts were tested against the yeast S. cerevisiae (Azhdarzadeh and Hojjati, 2016). From the species tested, this yeast is not included, however these MIC values give an ideia that MIC values would be higher than the ones tested, however if these concentrations where to be applied in a final product the organaleptic properties especially aroma would be compromised (Fisher and Phillips, 2008). Additionally, Caccioni et al assessed the antifungal activity of different citrus oils and found their effective doses to be ranging from 910.3 to 2180 ppm against $P$. digitatum, respectively (Caccioni et al., 1998 ) indicating once again the MIC values to be higher to the concentrations tested.

Cultured corn syrup is manufactured using a controlled food grade fermentation process being composed by organic acids and other natural fermentation-derived metabolites (Elsser-Gravesen and Elsser-Gravesen, 2014). Its efficacy is dependent upon pH, water activity, packaging/redox potential, storage conditions, temperature, humidity, salt, $\%$ solids, and/or presence of other antimicrobial compounds, information given by the supplier. The scenery repeats itself and the results using this commercial natural antimicrobial, respecting the usage limits discriminated in the technical sheet, are not positive having residual mycelial growth inhibition on few microorganisms tested, Chaetomium sp. and E. nigrum.Chaetomium sp. is more sensitive to the syrup than E. nigrum since its inhibition starts at a $0.05 \%(\mathrm{w} / \mathrm{V})$ rather than $0.09 \%(\mathrm{w} / \mathrm{V})$ on E. nigrum. These results are supported by work done Al-Zoreky where he tested in incorporated agar, Microgard, a commercially available fermented milk product on an unidentified black yeast, $P$. expansum and A. niger. The first two microorganisms showed some inhibition at $1 \%(\mathrm{w} / \mathrm{V})$ Microgard, on the other hand A. niger was tolerant to 5\% (w/V) Microgard and no MIC values could be obtained (Al-Zoreky et al., 1991).

Also, the supplier tested $0.5 \%(\mathrm{w} / \mathrm{V})$ of the same tested cultured corn syrup in apple, cherry and cream cheese fillings, inoculating them with a 2-log cocktail of mold isolates and no mold was observed at day 77 which indicates antifungal activity which go against the results obtained. However, in situ results can differ from the ones obtained in vitro.

Potassium sorbate, the chemically derived preservative is known to inhibit the growth of food-related yeasts and moulds like Candida, Cryptococcus, Saccharomyces, Aspergillus, Mucor and Penicillium, among others (Davidson et al., 2005). Data obtain in past projects done at FRULACT show that potassium sorbate has antifungal activity against all the tested microorganisms where at $0.5 \%(\mathrm{w} / \mathrm{V})$ all the species where $100 \%$ inhibited (dos Santos, 2016). From the data obtained natural vanillin at the same concentration could eventually substitute potassium sorbate, however further studies to evaluate the perfor- 
mance of vanillin in food-products are a must.

As a final note, it is important to refer that the biomass used in each PDA Petri plate in the poisoned growing media technique is not the same; it varies from specie to specie and from plate to plate. Due to this important factor it can not stated with $100 \%$ certainty the values obtained of MIC (Klančnik et al., 2010; Balouiri et al., 2016). Furthermore, the biomass used influences the growth diameters and the calculations done are also not $100 \%$ precise, an alternative would be to use dilution methods since they are consider to be the most appropriate to determinate MIC values (Balouiri et al., 2016). Having this in mind, the main objective of implementing this method was to simulate an environmental contamination, hence its variability in biomass concentration may be plausible.

\subsection{Conclusions}

The only natural antimicrobial which was $100 \%$ effective against all the tested microorganisms was the natural extracted vanillin at $5 \%(\mathrm{~m} / \mathrm{V})$. The citrus extract showed some positive results, however it did not show the same efficacy as the natural extracted vanillin. The rest of the natural antimicrobials showed little antifungal activity.

Since the ideal method to determine MIC value of the enzyme was not used, the lactoperoxidase-system was further tested in situ in fruit preparations and dosage yogurt in the next chapter.

Another important conclusion is that when comparing all the results spore forming fungi Aspergillus sp. and Penicillium sp. are the most resistant species as expected and only vanillin could inhibited its growth by $100 \%$. Regarding yeasts $P$. anomala reveal to be the most resistant microorganism.

Given these results, vanillin, organic citrus extract and lactoperoxidase were applied to fruit preparations and their performance was studied as potential preservatives and substitutes of potassium sorbate. This matter is adressed in the next Chapters. 


\section{Chapter 4}

\section{Testing the selected natural antimicrobials in fruit preparations and yogurt}

\subsection{Introduction}

The increasing demand for healthier products containing less additives led to various changes in the quality, safety and in the constitution of food ingredients. The natural antimicrobials are widely available from various natural sources, such as plant, animals and microorganisms, being part of the host mechanisms against microbial infections (Brul and Coote, 1999). Many factors can influence the selection of these natural antimicrobials such as its functional properties, availability, price, costumer awareness and their effect on the sensory attributes of the final product (Perumalla and Hettiarachchy, 2011). From the in vitro results obtained in Chapter 3, the selected natural antimicrobials, vanillin and organic citrus extract were tested in fruit preparations and dosed in yogurt.

Vanillin is widely used as a flavoring compound and for its antifungal and bacteriostatic properties (López-Malo et al., 1995; Cerrutti and Alzamora, 1996; Rupasinghe et al., 2006; Delves-Broughton, 2012). For this, it is used as a flavor additive per excellence in ice cream, soft drinks, chocolate confectionery, candy, baked goods, cakes, puddings, cookies, eggnogs and liquors, so its organoleptic feature is not strange for consumers (López-Malo et al., 1995). Citrus extract not only lend themselves to be used in food but also are GRAS and have been found to be inhibitory both in direct oil and vapor against a wide range of both Gram-positive, Gram-negative bacteria, yeasts and molds, however its pungent flavor may be a problem between consumers (Fisher and Phillips, 2008). These antimicrobials are going to be incorporated into fruit preparations, whose 
application is the incorporation in yogurt. Yogurt has been recognized as a healthy food due to its nutritional properties and health benefits providing a balance in the microbial population in the digestive tract (Lourens-Hattingh and Viljoen, 2001). So the maintenance of the yogurt microflora is an important issue to have in mind when using natural antimicrobials. The addition of these "natural preservatives" should maintain its stability during the shelf life of the yogurt and well as not interfere with the bacteria present.

In this Chapter, the antifungal efficiency of the natural antimicrobials as well as its stability during the pasteurization process and shelf life of the product were addressed. The fruit preparations containing selected antimicrobials and related dosed yogurts were monitored over time for their microbiological stability and for their ability to prevent artificial contaminations. Also, the stability of the lactic cultures: Lactobacillus bulgaricus present in yogurt were analyzed. In the end the organoleptic propertied of the novel developed yogurts were assessed by a random panel of 10 tasters.

\subsection{Materials and methods}

\subsubsection{Forest fruit preparations}

A mass of $500 \mathrm{~g}$ of forest fruit preparation was made by adding all the ingredients in a pan and heating them until pasteurization temperature was reached $\left(90^{\circ} \mathrm{C}\right)$. The pasteurization process was held at $90{ }^{\circ} \mathrm{C}$ for 4 minutes. The composition of the fruit preparation is discriminated in Table 4.1. The antimicrobial refers to the potassium sorbate added at $0.1 \%(\mathrm{w} / \mathrm{w})$ or vanillin and organic citrus extract added to different preparations at $0.5 \%$ $(\mathrm{w} / \mathrm{w})$. These compounds were added after (at around $55^{\circ} \mathrm{C}$ ) or before the pasteurization period to test its stability during this process. Additionally a control fruit preparation, with no antimicrobial, was prepared.

\subsection{2 ${ }^{\circ}$ Brix, $\mathrm{pH}$ and viscosity}

Standard parameters used by FRULACT were measured. ${ }^{\circ}$ Brix was measured using an automatic refractometer (Bellingham + Stanley, United Kingdom). The $\mathrm{pH}$ values were measured using a digital $\mathrm{pH}$ meter with automatic temperature control (Consort 6860 Hanna Instruments). The viscosity was measured using bostwick (CSC Scientific) 
Table 4.1: Different components of the fruit preparations. The exact components are not revealed due to confidentiality clauses. The water percentage may suffer little changes depending on the antimicrobial added.

\begin{tabular}{cc}
\hline Ingredient & $\%(\mathbf{w} / \mathbf{w})$ \\
\hline Fruit & 55.0 \\
Water & 35.2 \\
Concentrate fruit pure & 4.8 \\
Thickeners & 3.5 \\
pH controls & 0.5 \\
Flavoring agents & 0.3 \\
Sweeteners & 0.2 \\
Antimicrobial & - \\
\hline
\end{tabular}

\subsubsection{Simulation of an environmental contamination}

Some of the fruit preparations were artificially contaminated with a cocktail of Penicillium sp. and Aspergillus sp. . Plates number 7 and 11 A (Table A.1) were use to produce this inoculum. This inoculum was prepared according to Guarro et al.. After the stains were cultured in PDA plates for 7 days at $25{ }^{\circ} \mathrm{C}$, the surface of the Petri dishes was flooded with $10 \mathrm{~mL}$ of sterile distilled water. The suspensions obtained from both Petri plates were mixed and collected into a common vial. Afterwords, this suspension was diluted 10 times and used as the contaminating inoculum. The inoculum was then characterized by serial dilutions on DRBC plates and an estimation of CFU/mL was done. The fruit preparations were then contaminated by adding $5 \mathrm{~mL}$ of inoculum to $500 \mathrm{~g}$ of the fruit preparation to obtain a final concentration of $1 \%$ (v/w) (Guarro et al., 1998).

\subsubsection{Resume table}

In order to facilitate the understanding of the variability in the fruit preparation tested, a resume Table 4.2 is presented.

\subsubsection{Microbiological analysis of the fruit preparations}

\section{Sample preparations}

Samples of $10 \mathrm{~g}$ of the fruit preparations were collected into $90 \mathrm{~mL}$ of sterile BPW (VWR Chemicals, Belgium). This mixture was blended in a BagMixer $\AA$ (400P interscience) for 120 seconds in a stomacher bag (International Organization for Standardization, 2008). This process was carried out in duplicates.

\section{Enumeration of yeasts and molds}


Table 4.2: Resume table of the different conditions tested in fruit preparations. The third column refers to the addition of the antimicrobials after or before the pasteurization process. - represents the situation where the variable indicated was not tested

\begin{tabular}{cccc}
\hline Number & Antimicrobial & Pasteurization & Contamination \\
\hline $\mathbf{1}$ & Potassium sorbate & After & No \\
$\mathbf{2}$ & None & - & No \\
$\mathbf{3}$ & Organic citrus extract & After & No \\
$\mathbf{4}$ & Organic citrus extract & After & Yes \\
$\mathbf{5}$ & Organic citrus extract & Before & No \\
$\mathbf{6}$ & Organic citrus extract & Before & Yes \\
$\mathbf{7}$ & Vanillin & After & No \\
$\mathbf{8}$ & Vanillin & After & Yes \\
$\mathbf{9}$ & Vanillin & Before & No \\
$\mathbf{1 0}$ & Vanillin & Before & Yes \\
\hline
\end{tabular}

The enumeration of yeasts and molds was done respecting ISO 21527:2008. The culture media used for the enumeration was DRBC (VWR Chemicals, Belgium). The microorganisms were cultivated using the spread plate method where $0.1 \mathrm{~mL}$ of sample of the dilution $\left(10^{-1}\right)$ was pipetted onto the surface of a plate containing sterile solid DRBC. The sample was then spread over the media surface using a sterile glass spreader. This procedure was done in duplicate. The dishes were then incubated at $25 \pm 1{ }^{\circ} \mathrm{C}$, for at least $5 \pm 2$ days (International Organization for Standardization, 2008).

\subsubsection{Dosage in yogurt}

When the fruit preparation had at least 7 days (representing the time that they would, hypothetically be used by a client of FRULACT's) they were applied to stirred yogurt (Mimosa plain yogurt) at dosages of $15 \%$.

\subsubsection{Microbiological analysis of the yogurt}

\section{Sample preparations}

Samples of $10 \mathrm{~g}$ of yogurt were collected into $90 \mathrm{~mL}$ of sterile BPW (VWR Chemi-

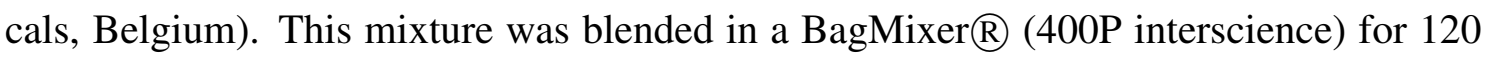
seconds in a stomacher bag. After 30 minutes of contact time, serial dilutions until $10^{-6}$ in $9 \mathrm{~mL}$ BPW vials were prepared (International Organization for Standardization, 2008). This process was done in duplicate.

\section{Enumeration of yeasts and molds}


The enumeration of yeasts and molds was done respecting ISO 21527:2008. The culture media used for the enumeration was DRBC (VWR Chemicals, Belgium). The microorganisms were cultivated using the spread plate method where $0.1 \mathrm{~mL}$ of sample of the dilution $\left(10^{-1}\right)$ was pipetted onto the surface of a plate containing sterile solid DRBC. The sample was then spread over the media surface using a sterile glass spreader. This procedure was done in duplicate. The dishes were then incubated at $25 \pm 1{ }^{\circ} \mathrm{C}$, for at least $5 \pm 2$ days (International Organization for Standardization, 2008).

\section{Enumeration of the viable cells in yogurt}

The microorganisms were cultivated on selective media Man, Rogosa and Sharpe (MRS) (VWR Chemicals, Belgium) using the drop technique. A drop of $20 \mu \mathrm{L}$ of all the dilutions (until $10^{-6}$ ) was pipeted onto the agar plates for the enumeration of L. bulgaris. The cultures were then incubated at $37^{\circ} \mathrm{C} \pm 2{ }^{\circ} \mathrm{C}$ during 3 days (Michael et al., 2010)

\subsubsection{Evaluation of organoleptic properties}

A group of 10 non-experts evaluated the organoleptic properties of the developed yogurts in terms of sweetness, acidity, astringency, and flavor when comparing them with a control. The questionnaire in present in Figure B.1 in the Appendix B.

\subsubsection{Statistical analysis}

Statistical significant differences, when applicable, was tested using t-Student's test in Microsoft Excel. The value of $\mathrm{p}$ for the rejection was set to $\mathrm{p}<0.05$.

\subsection{Results and discussion}

\subsubsection{Effect of vanillin and citrus extract in microbiology load of fruit preparations}

Forest fruit preparations with vanillin and organic citrus extract were monitored over time for the assessment of their fungal load. It is important to refer that for the company, the quantification of yeast and molds should be under the detectable level and any preparation whose microbiological analysis revealed just a single colony ought to be rejected. The fruit preparations were subjected to a pasteurization process at $90{ }^{\circ} \mathrm{C}$ and any contamination is very unlikely to be due the initial raw materials fungal load, unless they are thermoresistant. Possible sources of contamination include the natural antimicrobials 
once they were added after the process, or environmental contamination. However, microbiological analysis in DRBC were done to the tested antimicrobials, and no colony was detected, so this excludes them as a possible source of contamination. 24 hours after the preparations were done $\mathrm{pH},{ }^{\circ}$ Brix and viscosity were measured and are shown in Table 4.3

Table 4.3: $\mathrm{pH},{ }^{\circ}$ Brix and viscosity values of the different fruit preparations done. The third column refers to the addition of the antimicrobials after or before the pasteurization process. - represents the situation where the variable indicated was not tested

\begin{tabular}{cccccc}
\hline Number & Antimicrobial & Pasteurization & $\mathbf{p H}$ & ${ }^{\mathbf{0}}$ Brix & Viscosity $(\mathbf{c m} / \mathbf{6 0} \mathbf{s}$ at 20 \\
\hline $\mathbf{~} \mathbf{C})$ \\
$\mathbf{2}$ & Potassium sorbate & After & 3.60 & 7.7 & 5.0 \\
$\mathbf{3}$ & None & - & 3.83 & 9.2 & 3.5 \\
$\mathbf{4}$ & Organic citrus extract & After & 3.81 & 9.3 & 5.0 \\
$\mathbf{5}$ & Organic citrus extract & After & 3.84 & 8.5 & 5.0 \\
$\mathbf{6}$ & Organic citrus extract & Before & 3.82 & 8.4 & 6.5 \\
$\mathbf{7}$ & Organic citrus extract & Before & 3.81 & 8.7 & 6.5 \\
$\mathbf{8}$ & Vanillin & After & 3.78 & 9.4 & 5.8 \\
$\mathbf{9}$ & Vanillin & After & 3.82 & 9.1 & 5.8 \\
$\mathbf{1 0}$ & Vanillin & Before & 3.82 & 9.8 & 6.0 \\
\hline
\end{tabular}

Regarding the parameters measured, all are between the specification set for this forest fruit preparations by FRULACT where $\mathrm{pH}$ values should be $3.80 \pm 0.20^{\circ} \mathrm{Brix} 8.0 \pm 2.0$ and viscosity $7.0 \pm 2.0(\mathrm{~cm} / 60 \mathrm{~s})$ at $20{ }^{\circ} \mathrm{C}$. All present similar values of ${ }^{\circ} \mathrm{Brix}$ and $\mathrm{pH}$ around 3.80 which makes them prone for yeast contamination's (Legan and Voysey, 1991).

Ideally the fruit preparations would be analyzed during at least 90 days since its consider to be the maximum time that FRULACT guaranties its microbiological safety when a preservative is added, nonetheless time limitations led the analysis to occur only until day 51 to 53 . When analyzing the fruit preparation without no propose contamination, the preparations did not develop any fungal load at detectable levels when potassium sorbate, vanillin or organic citrus extract (added after the pasteurization process). The fruit preparation without any antimicrobial starting showed signs of contamination at day 46 whereas the fruit preparation with organic citrus extract added before the pasteurization process showed earlier signs of contamination at day 30 of analysis. However, there was no visible mycelium growth in all fruit preparations as it can be seen in Figure 4.1. This is though to be because when applicable the fungal load was little and inferior of $3 \log 10$ (CFU/g). 


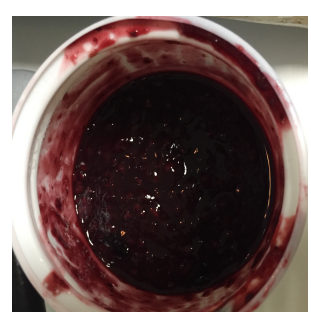

(a) No antimicrobial

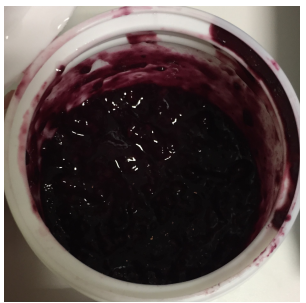

(d) Vanillin added after the pasteurization

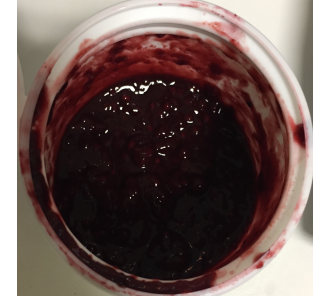

(b) Potassium sorbate

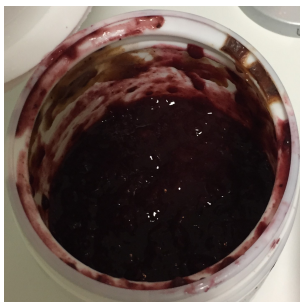

(e) Organic citrus extract added before the pasteurization

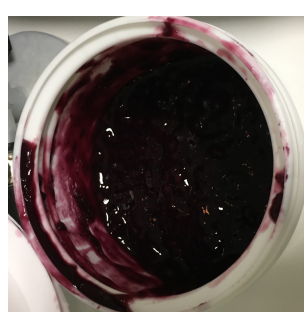

(c) Vanillin added before the pasteurization

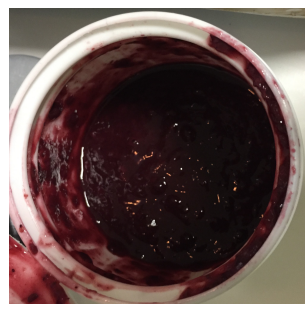

(f) Organic citrus extract added after the pasteurization

Figure 4.1: Aspect of the fruit preparations containing potassium sorbate, organic citrus extract, vanillin or no antimicrobial after 51 to 53 days of refrigerated storage at $4{ }^{\circ} \mathrm{C}$

Analyzing the results obtained in both tested fruit preparations containing vanillin, they followed the tendency from the positive control. Hence, vanillin does not lose its activity during the pasteurization process an can successfully extend the shelf life of the fruit preparations and potential substitute potassium sorbate as predicted by other authors (López-Malo et al., 1995; Cerrutti and Alzamora, 1996; Fitzgerald et al., 2004; Yuan et al., 2013). In the next section the potential of vanillin will be further discussed.

Regarding the use of the organic citrus organic as a potential natural antimicrobial, the results differ. After 30 days of storage, the fruit preparations containing this antimicrobial showed fungal growth increasing its load until the last day of analysis. Considering that the fruit preparations with the same antimicrobial but added after the pasteurization process did not show any signs of fungal contamination, the pasteurization process may have inactivated the citrus extract which contradicts the information given by the supplier where a stability until $121{ }^{\circ} \mathrm{C}$ was assured. Also, since the volatile part of the citrus extract have a major influence on its antimicrobial efficiency, subjecting this antimicrobial to a pasteurization process may have evaporated these components leading to a lower microbiological efficacy (Saiyasombati and Kasting, 2003). With these results it can be concluded that the organic citrus extract could possible substitute potassium sorbate however an additional step has to be added to the production process of the fruit preparations and the antimicrobial ought to be added after the pasteurization step. 


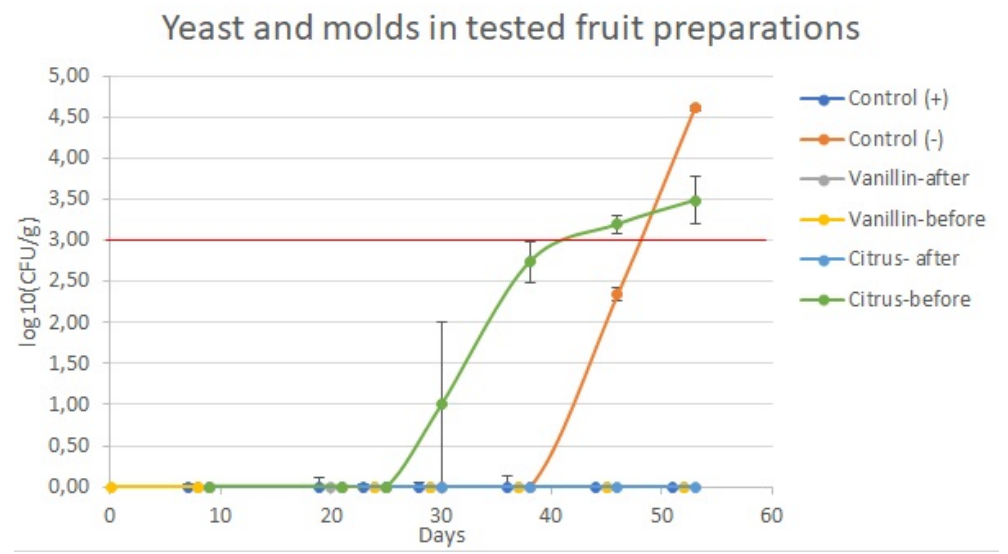

Figure 4.2: Fungal load of fruit preparations containing organic citrus extract, vanillin, potassium sorbate (control (+)) or no antimicrobial (control (-)) during 51 to 53 days of cold storage at $4{ }^{\circ} \mathrm{C}$. The bullet points represent the average values and the bars the standard deviation. "Citrus-after" and "Vanillin-after" represents the tendency of the fruit preparation where the natural antimicrobial was added after the pasteurization process. "Citrus-before" and "Vanillin-before"represents the tendency of the fruit preparation where the natural antimicrobial was added before the pasteurization process. The red line represents the detection limit of the technique.

In addition, FRULACT guaranties that preparations without any antimicrobial can endure until 60 days, since the containers were opened several times the appearance of molds in the fruit preparation with no antimicrobial can be justified. The analysis were done in these way to simulate a higher possibility for an environmental contamination. Also, the temperature of storage may have influenced the fungal growth since it it well know that at low temperatures, in this case at $4{ }^{\circ} \mathrm{C}$, microorganisms optimal growth is affected (Ayerst, 1969).

\subsubsection{Effect of vanillin and citrus extract in artificially contaminated fruit preparations}

The ability of both vanillin and the organic citrus extract to prevent an hypothetical contamination caused by an environmental fungi contamination was tested by artificially contaminating the fruit preparations. The fungi used were Penicillium sp and Aspergillus sp. due to their capability to survive in harsh environments and spoilage tendency. The inoculum had an initial load of $5.06 \pm 0.05 \log 10(\mathrm{CFU} / \mathrm{mL})$ and was added at day 4 of the storage time of the preparations. The fungal load of the fruit preparations was monitored over 52 days in case of vanillin and 25 days in case of the preparations containing the 
citrus extract since mycelium growth appeared on the $25^{\text {th }}$ day as it can be observed in Figure 4.3 and the results in graph form are present in Figure 4.4.

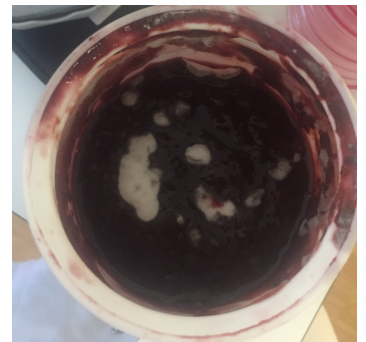

(a) Fruit preparation with the organic citrus extract added after the pasteurization process

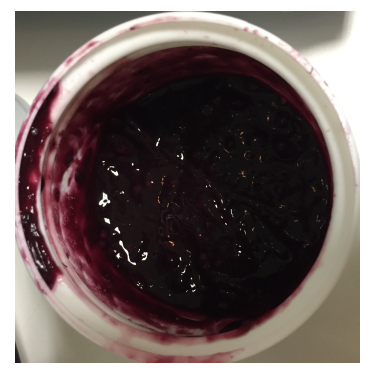

(c) Fruit preparation with vanillin added before the pasteurization process

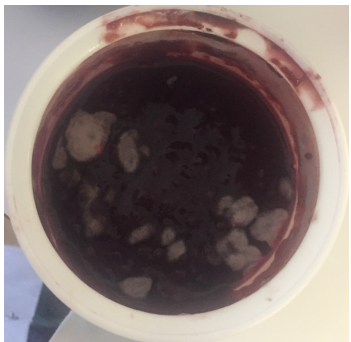

(b) Fruit preparation with the organic citrus extract added before the pasteurization process

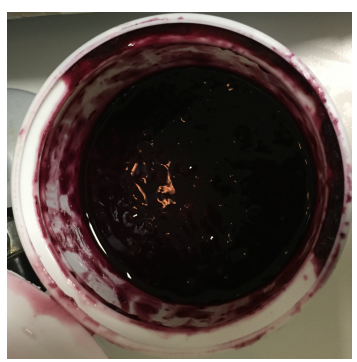

(d) Fruit preparation with vanillin added after the pasteurization process

Figure 4.3: Aspect of the fruit preparations containing organic citrus extract or vanillin after 25 and 52 days respectively of refrigerated storage at $4{ }^{\circ} \mathrm{C}$

In both situations, all preparations started approximately with the same fungal load of around $4 \log 10(\mathrm{CFU} / \mathrm{g})$ and successfully controlled the proliferation of the contamination. In the case of the organic citrus extract there was a reduction of $1 \log 10(\mathrm{CFU} / \mathrm{g})$ in both tested fruit preparations. There was a clear reduction in the log count, suggesting that the extract mantained its activity after the pasteurization process as indicated in the study done by Jeong (Jeong et al., 2004). Clearly, there was a reduction in fungal load, however visible mycelium growth could be observed, hence the analysis on this fruit preparation stooped since it is a critical factor to FRULACT. This was further consider to be mistake, posterior analysis would be interesting to see if the fungal load would continue regressing. However, potassium sorbate is known for this characteristic, inhibition of mycelium growth (Park et al., 2005), hence in order to substitute this preservative, the natural antimicrobial should be able to act is the some way which was not verified. Comparing this results with the ones obtained in the previous section there is a clear contradiction probably due to the variability of the pasteurization process since it was done manually. 


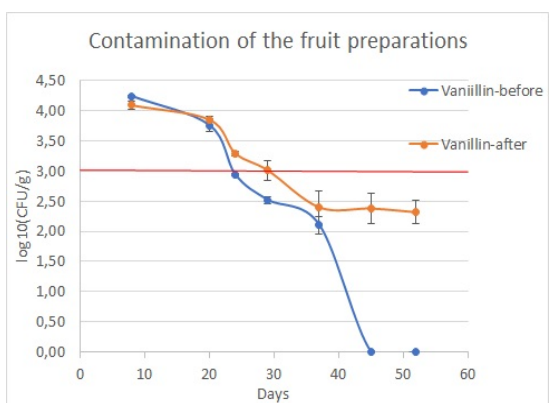

(a) Vanillin

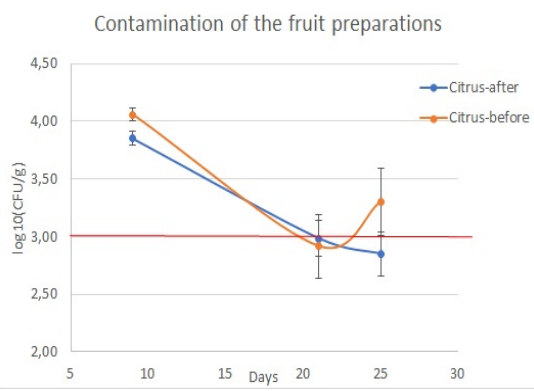

(b) Organic citrus extract

Figure 4.4: Fungal load of fruit preparations containing vanillin or organic citrus extract artificially contaminated over 52 or 25 days of cold storage at $4{ }^{\circ} \mathrm{C}$ respectively. The bullet points represent the average values and the bars the standard deviation. "Citrus-after" and "Vanillin-after" represents the tendency of the fruit preparation where the natural antimicrobial was added after the pasteurization process. "Citrus-before" and "Vanillinbefore" represents the tendency of the fruit preparation where the natural antimicrobial was added before the pasteurization process. The red line represents the detection limit of the technique

Maybe the pasteurization of these fruit preparations was not done as aggressively as the ones in the previous section and the citrus extract maintained its activity. On the other hand, these fruit preparations were only analyzed during 21 days instead of the 52 days, so the antimicrobial may also lose its stability over time once pasteurized and this could not be detected due to this time difference in analysis.

With vanillin, no visible mold and physical changes in color and texture were observed until day 52 of analysis as it can be seen in the Figure 4.3 which is a good sign since it inhibits mycelium growth. Again, there was a clear reduction in fungal load, in these case there was a bigger reduction of approximately 2 to $4 \log 10(\mathrm{CFU} / \mathrm{mL})$ as it can be seen in Figure 4.4. The obtained results are supported by literature. Similar results were obtained when Tomadoni achieved a reduction in more than $3 \log 10$ cycles of strawberry juice with the same concentrations of vanillin tested in the project (Tomadoni et al., 2016). Fitzgerald simulated a lower contamination of $10^{4} \mathrm{CFU} / \mathrm{mL}$ in apple juice and peach-flavored and $20 \mathrm{mM}$ vanillin completely inhibit the growth of the inoculated fungus (S. cerevisiae) during 8 weeks of storage at $25{ }^{\circ} \mathrm{C}$ (Fitzgerald et al., 2004). Addicionally the fungal reduction in both fruit preparations are identical and when doing a t-student test there were no significant differences $(p>0.05)$ which indicated that vanillin is functional and active in both cases hence resistant to the pasteurization process which is in concordance with research done by Yuan (Yuan et al., 2013). 


\subsubsection{Effect of vanillin and citrus extract in microbiology load and lactic cultures in fruit preparations dosed in yogurts}

In this part of the work, the effects of fruit preparations containing organic citrus extract or vanillin on yogurt were tested. The fruit preparations previously discussed were applied to yogurt when they were 28 to 30 days old and were analyzed during 23 days. Also, since the fruit preparations with the organic citrus extract and contamination were not viable at this point they were not applied onto yogurt.

The results for enumeration of L. bulgaricus in yogurts contain the natural antimicrobials are present in Figure 4.5. A positive and negative control with potassium sorbate and no antimicrobial were also monitored for comparison. There were some technical problems on the $16^{\text {th }}$ day of analysis and no data points could be obtained hence the gap in data points between the $8^{\text {th }}$ and $23^{r d}$ day.

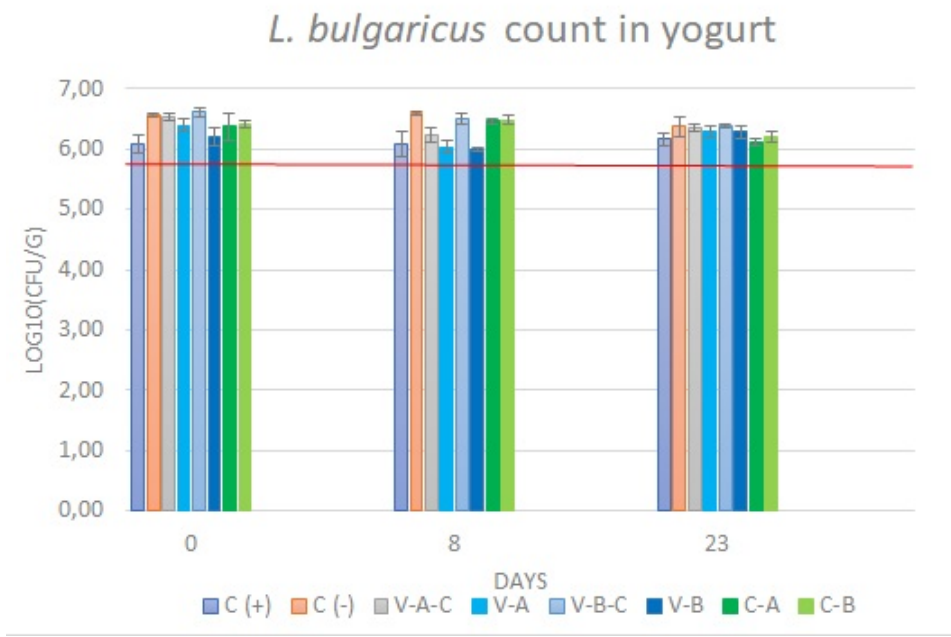

Figure 4.5: L. bulgaricus load of fruit preparations in dosed in yogurt containing organic citrus extract, vanillin, potassium sorbate $(\mathrm{c}(+))$ or no antimicrobial (c (-)) during 23 days of cold storage at $4{ }^{\circ} \mathrm{C}$. The bars represent the average values and the bars the standard deviation. "C-A" and "V-A" represents the tendency of the yogurt where the natural antimicrobial was added after the pasteurization process. "C-B" and 'V-B"represents the tendency of the yogurt where the natural antimicrobial was added before the pasteurization process. "V-B-C", V-A-C" represents the tendency of the yogurt where the natural antimicrobial was added before or after the pasteurization process, , correspondingly and were artificially contaminated. The red line represents the detection limit of the technique

All yogurts monitored maintained a $\log$ count around $6 \log 10(\mathrm{CFU} / \mathrm{mL})$ with values ranging from 6.08 to $6.89 \log 10(\mathrm{CFU} / \mathrm{mL})$. Having in mind that the graphs only have three points, when doing a statistical test no significant differences $(p>0.05)$ between the results with the controls (no antimicrobial and potassium sorbate) were observed. It 
can be inferred that the fruit preparations including the natural antimicrobials did not effect the yogurt natural microflora, which indicates that it is feasible to add them without affecting the lactic cultures present. This is also confirmed in the past when (Rezazadeh et al., 2015) obtained similar results with vanillin and (Michael et al., 2010) with citrus extracts once they applied these natural antimicrobials directly in yogurt.

These results show the addition of these natural extracted antimicrobials do not interfere with the viability of $L$. bulgaricus, however generally yogurt contained $10^{7}$ viable cells of L. bulgaricus per gram of yogurt (Donkor et al., 2006) a higher value that the one obtained. Other authors report that conventional yogurt counts range from 8.85 to 8.00 $\log 10(\mathrm{CFU} / \mathrm{mL}$ ) for the same bacteria (Cruz et al., 2013), again there is a $2 \log 10$ difference comparing to the obtained values. Also Portuguese legislation says that in yogurts, lactic cultures should be of $5 \times 10^{7}$ cells per gram of yogurt (Ministério, 1992). Since the results were similar in all tested yogurts, including the negative control, one can argue that the problem maybe of the initial yogurt or the technique used. Maybe the storage conditions at $4 \pm 2{ }^{\circ} \mathrm{C}$ were not ideal which caused the death of the lactic acid bacteria leading to a log count reduction or the managing of the yogurt during the experimental trial were not the best. Additionally, in FRULACT's history a log count of 6 is a standard value, which further validates the obtained results.

Regarding the yeast and mold analysis the results are present in Figure 4.6. It is important to say that the colony count was done even at values lower than 10, the lower detectable level established by the ISO 21527:2008 (International Organization for Standardization, 2008) because this values are of interest to FRULACT.

Log counts in general are very low and inferior to $2.5 \log 10$ (CFU/g) which indicates that when applicable colony counts where inferior to 10 . Previous results in the fruit preparations are confirmed by this graph. The contamination is being controlled by the natural preservative (vanillin) and by day 23 , in both preparations, the values are near 0 , similar values where obtained by Penney (Penney et al., 2004). When it comes to fruit preparations with just vanillin no colony count was obtained whereas with the organic citrus extract this is not confirmed. Even though the contamination is not very denotative the number of fungus increased over time, which indicates this preservative does not maintain the microbiological safety of the product during its self life.

\subsubsection{Evaluation of the organoleptic properties}

Different characteristics, acidity, sweetness, astringency and flavor, of yogurt containing fruit preparations with vanillin, organic citrus extract or potassium sorbate (standard) were evaluated by a panel of 10 tasters. 


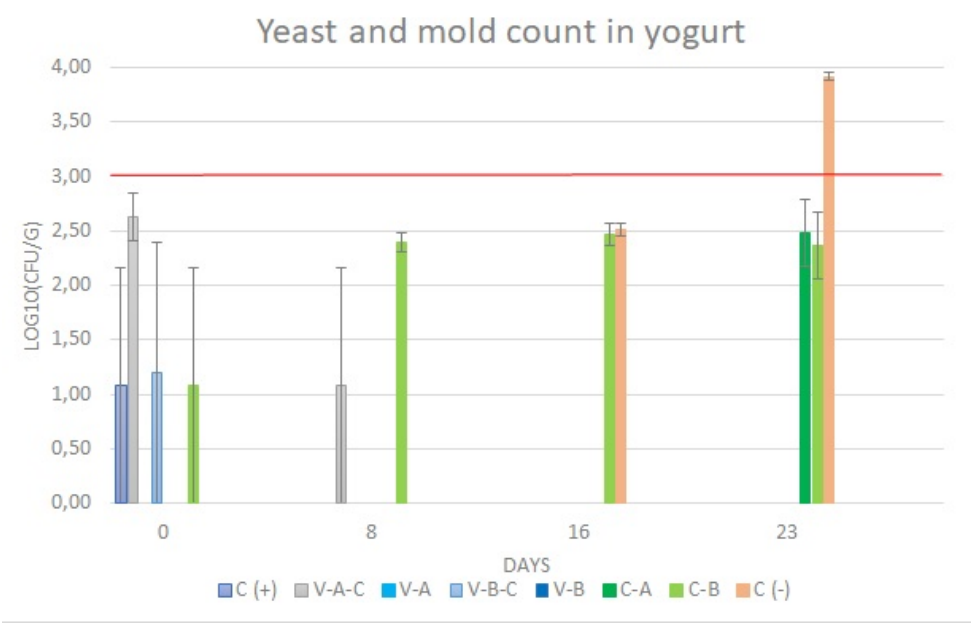

Figure 4.6: Fungal load of fruit preparations in dosed in yogurt containing organic citrus extract, vanillin, potassium sorbate (c (+)) or no antimicrobial (c (-)) during 23 days of cold storage at $4{ }^{\circ} \mathrm{C}$. The bars represent the average values and the bars the standard deviation. "C-A" and "V-A" represents the tendency of the yogurt where the natural antimicrobial was added after the pasteurization process. "C-B" and "V-B"represents the tendency of the yogurt where the natural antimicrobial was added before the pasteurization process. "V-B-C", V-A-C" represents the tendency of the yogurt where the natural antimicrobial was added before or after the pasteurization process, , correspondingly and were artificially contaminated. The red line represents the detection limit of the technique.

Even though the number of tasters is not very representative the opinions obtained in the questionnaire gave some idea of the costumers preferences . Regarding the acidity, there was no clear preference, around $40 \%$ found that both yogurt containing the antimicrobials were more acidic, however the other $60 \%$ consider to be have less or the same acidity when comparing to the standard sample. On the other hand, $70 \%$ of the population tested considered the yogurt with the citrus extract to be less sweet than the one with potassium sorbate, which could indicate that the organic citrus extract has a bitter effect on yogurt. Results with the vanillin are rather equitation and opinions differ, $30 \%$ fell the sweetness to be the same, another $30 \%$ considers it to be sweeter and $40 \%$ considers it to be less sweet, so no agreement was reached. When it comes to the astringency, $70 \%$ felt that the yogurt with the organic citrus extract was more astringent and the same percentage of the population considers the yogurt with the vanillin to have the same astringent as the control. So the main tendency is that vanillin seems to have no effect on the astringency whereas the organic citrus extract increases this parameter. The different perception of the tasters regarding the acidity, sweetness, astringency and are shown in Figure 4.7.

It was expected that the flavor would be influenced due to the intense flavor associated 


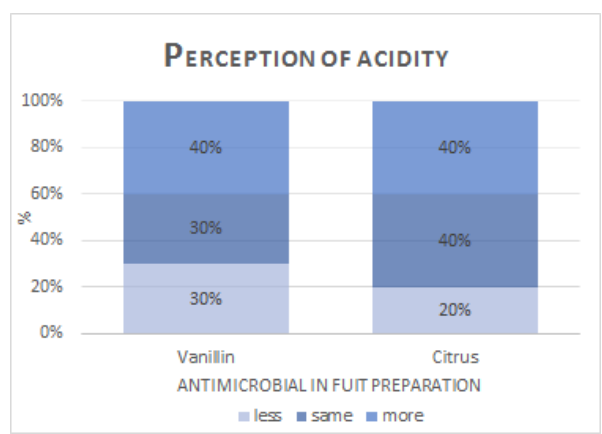

(a) Perception of the tasters of acidity

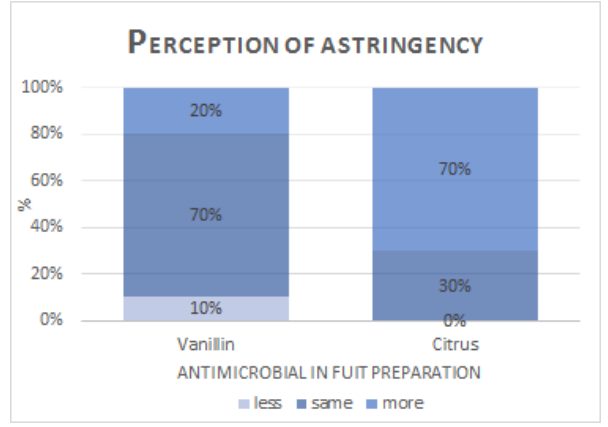

(c) Perception of the tasters of astringency

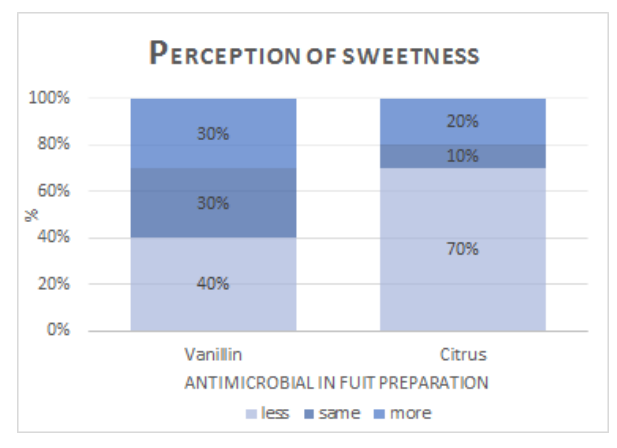

(b) Perception of the tasters of sweetness

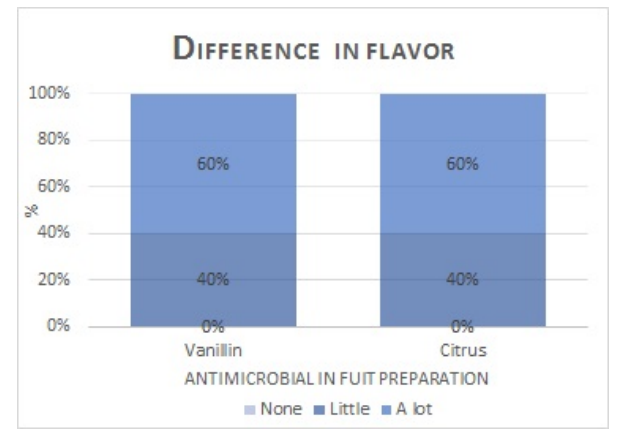

(d) Perception of the tasters of flavor

Figure 4.7: Perception of the tasters of acidity, sweetness, astringency and flavor when comparing the yogurts with fruit preparations containing vanillin or organic citrus extract with the standard (potassium sorbate)

to phenols present in the tested natural antimicrobials (Fisher and Phillips, 2008). This idea was reenforced has it can be seen in Figure $4.7 \mathrm{~d}$ when $100 \%$ of the tested population agrees that both antimicrobials influence the flavor. Perhaps in a bad way, since when it comes to preferences, $70 \%$ to $80 \%$ would rather eat the control yogurt then the ones with the natural antimicrobials. This lack of success when it came to taste may be related to the type of preparations that the antimicrobials were tested in. The choice when it came to the fruit preparations that the antimicrobials would be tested in was solely attributed having in mind the initial contamination of the raw materials, the bigger the better. Probably if the flavor of the antimicrobials could be masked by a different type of preparations, flavoring agents used the perception of the tested subject to the antimicrobials could be different.

\subsubsection{Price analysis}

As stated in the previous section the use of these natural antimicrobials can have a negative affect on the price of the final product. Using the prices from the suppliers of FRULACT, 


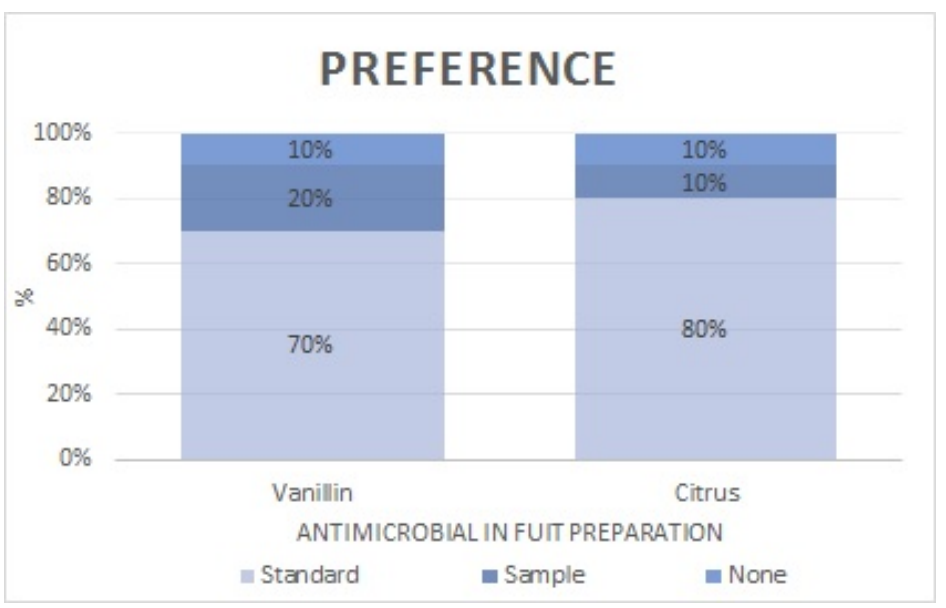

Figure 4.8: Preference of the tested subjects when comparing the yogurts with fruit preparations containing vanillin or organic citrus extract with the standard (potassium sorbate)

the fruit preparation with vanillin would cost between $5.00-6.00$ euros $/ \mathrm{kg}$ and with the organic citrus extract the price would decreased to $4.30-5.00$ euros $/ \mathrm{kg}$. Comparing these price ranges with the one from the fruit preparation with the potassium sorbate $(1.20$ 1.80 euros $/ \mathrm{kg}$ ) the increment would be of 2 to 3 times, so the final price to the consumer would have the same increase in value. The one thing to have in consideration is if the consumer will want to spend that much more money in order to get a "cleaner" product. Probably it would have to be considered a premium product and only a restrict group of people would be willing to buy it.

\subsection{Conclusions}

In this chapter the effect of vanillin and organic citrus extract on fruit preparations and dosed in yogurt was studied. In case of vanillin it successfully controlled the microbial load of the both fruit preparations and yogurt even when subjected to an artificial contamination during an average of 52 days of refrigerated storage. It also shown resistance to a pasteurization process held at $90{ }^{\circ} \mathrm{C}$ during 4 minutes and did not influence the natural microflora of yogurt.

When it came to the citrus extract, the results obtained revealed that the extract was not resistance to the pasteurization process and could not control an artificial contamination showing mycelium growth after 25 days. In a more positive note, it did not interfere with the stability of the lactic cultures present in yogurt.

In face of these facts, the natural extract vanillin showed the best results, very similar to the potassium sorbate and can possible subtitute potassium sorbate and be considered 
an effective natural antimicrobial. On the other had, if applied it will increase the price of the final product and have influence in the organoleptic properties of such. In addition it can not be said that vanillin assures microbiological safety since no testes on bacteria were done and at this point it is not known how it would control bacterial spoilage. Even tough at a low $\mathrm{pH}$ these mater in not a problem, since this has been a big problem in food industry (Raybaudi-Massilia et al., 2009) it should be an interesting point to be studied in future work. 


\section{Chapter 5}

\section{Testing lactoperoxidase in FruIdentity strawberry preparation and yogurt}

\subsection{Introduction}

Yogurt is a very popular fermented milk being produced all over the world. It is consider to have a high nutritional value and positive bioactive effects, usually reinforced by the addition of prebiotic ingredients and probiotic bacteria. Strawberry yogurt is among the most common fermented dairy products consumed (Oliveira et al., 2015).

FruIdentity stawberry preparations is a product of high value to FRULACT and one of the goals of the company is to substitute potassium sorbate for a natural alternative. However this fruit preparation is not pasteurized which is an additional problem and possible cause for spoilage.

Lactoperoxidase is a natural occurring glycoprotein enzyme in raw milk and can play an active role in the keeping quality of raw and pasteurized milk (Seifu et al., 2005; Taylor, 2014) exhibiting inhibitory activity against several bacteria and fungus. Since the FruIdentity strawberry is not pasteurized at which could compromise the activity of the enzyme, inactivating it (Kussendrager and van Hooijdonk, 2000; Seifu et al., 2005) this natural antimicrobial can be possible used in this product.

Even though there was no success in testing lactoperoxidade in vitro as it can be seen in Chapter 3, it is though that the method used was not ideal and potentially in a fruit matrix the results may differ. Therefore, in this Chapter lactoperoxidade was tested in FruIdentity strawberry preparation and in dosage yogurt. The microbial load was monitored as well as the microflora stability present in yogurt. 


\subsection{Materials and methods}

\subsubsection{FruIdentity strawberry preparations}

$500 \mathrm{~g}$ of FruIdentity strawberry were made and the composition of the fruit preparation is discriminated in Table 5.1. The process starts by adding all the ingredients, except the fruit and the lactoperoxidade, in a pan and subjecting then to a pasteurization process. This process is held at $90{ }^{\circ} \mathrm{C}$ during 4 minutes. Afterwards, this sugar syrup was pored over the fruit. Later on, a $0.5 \%(\mathrm{w} / \mathrm{w})$ lactoperoxidse solution was added to this fruit preparation. Additionally, a negative and a positive control, with no antimicrobial and potassium sorbate at $0.1 \%(\mathrm{w} / \mathrm{w})$ respectively were done.

Table 5.1: Different components of the FruIdentity strawberry. The exact components are not revealed due to confidentiality clauses. The antimicrobial refers to the potassium sorbate or lactoperoxidase that was added to different preparations. The water percentage may suffer little changes depending on the antimicrobial added.

\begin{tabular}{cc}
\hline Ingredient & $\%(\mathrm{w} / \mathrm{w})$ \\
\hline Strawberry & 61.5 \\
Sugar & 28.0 \\
Water & 8.9 \\
pH control & 0.8 \\
Firming agent & 0.2 \\
Antimicrobial & - \\
\hline
\end{tabular}

\subsubsection{Microbiological analysis of the fruit preparations}

\section{Sample preparations}

Samples of $10 \mathrm{~g}$ of the fruit preparations were collected into $90 \mathrm{~mL}$ of sterile BPW

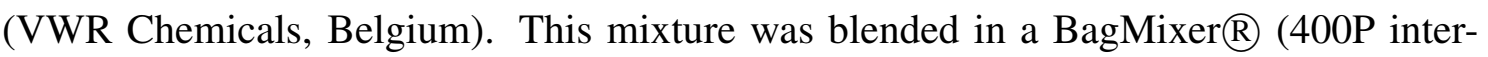
science) for 120 seconds in a stomacher bag (International Organization for Standardization, 2008). This process was done in duplicate.

\section{Enumeration of yeasts and molds}

The enumeration of yeasts and molds was done respecting ISO 21527:2008. The culture media used for the enumeration was DRBC (VWR Chemicals, Belgium). The microorganisms were cultivated using the spread plate method where $0.1 \mathrm{~mL}$ of sample of the dilution $\left(10^{-1}\right)$ was pipetted onto the surface of a plate containing sterile solid DRBC. The sample was then spread over the media surface using a sterile glass spreader. 
This procedure was done in duplicate. The dishes were then incubated at $25 \pm 1{ }^{\circ} \mathrm{C}$, for at least $5 \pm 2$ days (International Organization for Standardization, 2008).

\subsubsection{Dosage in yogurt}

When the fruit preparation had at least 7 days (representing the time that they would, hypothetically be used by a client of FRULACT's) they were applied to stirred yogurt (Mimosa plain yogurt) at dosages of $15 \%$.

\subsubsection{Microbiological analysis of the yogurt}

\section{Sample preparations}

Samples of $10 \mathrm{~g}$ of yogurt were collected into $90 \mathrm{~mL}$ of sterile BPW (VWR Chemi-

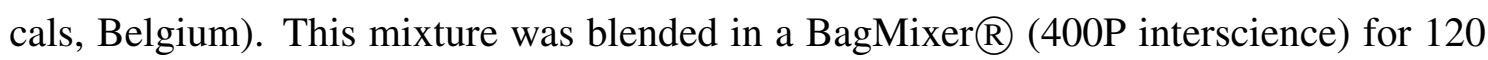
seconds in a stomacher bag. After 30 minutes of contact time, serial dilutions until $10^{-6}$ in $9 \mathrm{~mL} \mathrm{BPW}$ viles were prepared (International Organization for Standardization, 2008). This process was done in duplicate.

\section{Enumeration of yeasts and molds}

The enumeration of yeasts and molds was done respecting ISO 21527:2008. The culture media used for the enumeration was DRBC (VWR Chemicals, Belgium). The microorganisms were cultivated using the spread plate method where $0.1 \mathrm{~mL}$ of sample of the dilution $\left(10^{-1}\right)$ was pipetted onto the surface of a plate containing sterile solid DRBC. The sample was then spread over the media surface using a sterile glass spreader. This procedure was done in duplicate. The dishes were then incubated at $25 \pm 1{ }^{\circ} \mathrm{C}$, for at least $5 \pm 2$ days (International Organization for Standardization, 2008).

\section{Enumeration of the viable cells in yogurt}

The microorganisms were cultivated on selective media Man, Rogosa and Sharpe (MRS) (VWR Chemicals, Belgium) using the drop technique. A drop of $20 \mu \mathrm{L}$ of all the dilutions (until $10^{-6}$ ) was placed onto the agar plates for the enumeration of Lactobacilus bulgaris. The cultures were then incubated at $37{ }^{\circ} \mathrm{C} \pm 2{ }^{\circ} \mathrm{C}$ during 3 days (Michael et al., 2010) 


\subsection{Results and discussion}

\subsubsection{Effect of lactoperoxidase in the microbiology load of FruIden- tity strawberry preparations}

These fruit preparations with lactoperoxidase were monitored over time for the assessment of their fungal load. Once again, low colony counts, inferior to the legally accepted limit were considered since it is of interest to FRULACT. In this case the source of contamination include the natural antimicrobials, the raw material used (strawberries) since there was no pasteurization and possible environmtal contamination.However, microbiological analysis in DRBC were done on the lactoperoxidase, and no colony was detected, so this excludes it as a possible source of contamination.

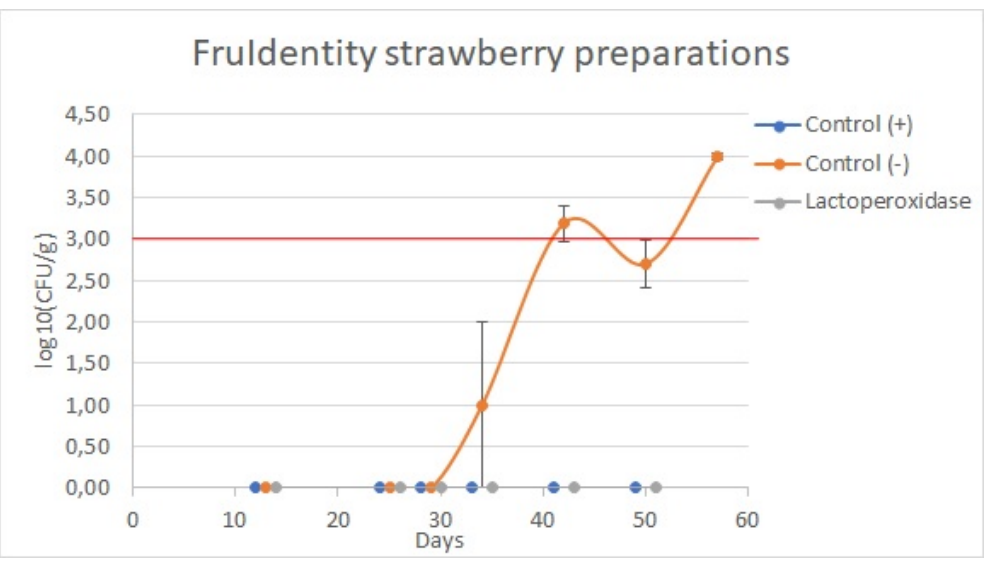

Figure 5.1: Fungal load of fruit preparations containing lactoperoxidase, potassium sorbate (controlo (+)) or no antimicrobial (control (-)) during 58, 57 and 56 days correspondingly of cold storage at $4{ }^{\circ} \mathrm{C}$. The bullet points represent the average values and the bars the standard deviation. The red line represents the detection limit of the technique.

The motorization of the fruit preparations was done during 56 to 58 days depending on the antimicrobials used in fruit preparation, since FRULACT assures microbiological safety up to 30 days at $0-10{ }^{\circ} \mathrm{C}$ when a preservative is added and no pasteurization process is held, the time of analysis was extended up to 20 days. The results obtained are present in Figure 5.1. When analyzing the fungal load only the positive control, without any antimicrobial showed microbial load starting in day 34 of analysis and in day 56 of analysis visible mold could be observed in this fruit preparation (Figure 5.2). On a positive note neither the fruit preparations with potassium sorbate or the lactoperoxidase showed any fungal load though the time of analysis and no visible mold was observed on the surface of the preparations. The fruit preparations containing the lactoperoxidase 
behaved as the positive control, meaning it would be a potential substitute for potassium sorbate assuring microbiological safety of the preparations done at FRULACT. Although tests on strawberry preparations have not been conducted yet, results in apple juices (Popper and Knorr, 1997) were and a similar conclusion has been drawn. A combination of $5 \mathrm{U} / \mathrm{mL}$ of the lactoperoxidase system with $1 \mathrm{U} / \mathrm{mL}$ glucose oxidase could control an artificial contamination of $10^{-5} \mathrm{CFU} / \mathrm{mL}$ of $S$. cerevisiae and Rhodutorula rubra. Also, Touch et al. could reduce more than $5 \log 10(\mathrm{CFU} / \mathrm{mL})$ of $S$. enteritidis in tomato juice treated with $14.8 \mu \mathrm{g} / \mathrm{mL}$ of a lactoperoxidase system after 3 (acid-adapted cells) and $4 \mathrm{~h}$ (nonadapted cells) of storage at $30^{\circ} \mathrm{C}$. (Touch et al., 2004).

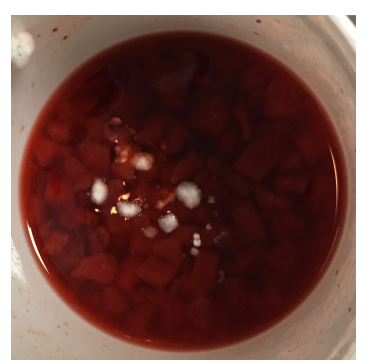

(a) No antimicrobial

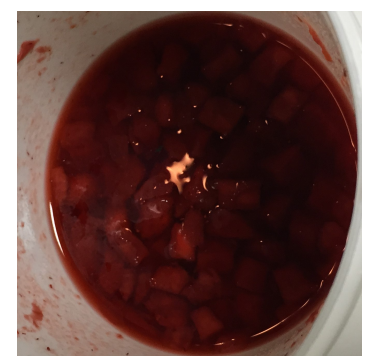

(b) Potassium sorbate

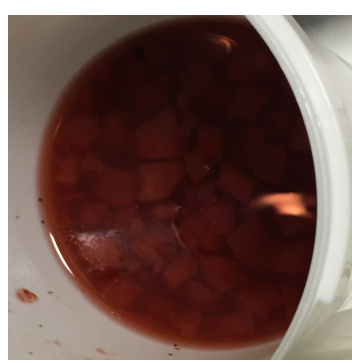

(c) Lactoperoxidase

Figure 5.2: Aspect of the fruit preparations containing potassium sorbate, lactoperoxidase or no antimicrobial after 56 to 58 days of refrigerated storage at $4{ }^{\circ} \mathrm{C}$

\subsubsection{Effect of lactoperoxidase in the microbiology load and lactic cultures in FruIdentity strawberry preparations dosed in yo- gurt}

In this subsection, the effects of these fruit preparations were tested onto yogurt. These application onto yogurt was done when they were between 33 to 35 days old and microbiological analyzes occurred for 23 days.

The results regarding the enumeration of L. bulgaricus in yogurts are present in Figure 5.3.A positive and negative control with potassium sorbate and no preservative were also monitored for comparison. There were some technical problems on the $16^{\text {th }}$ day of analysis and no data points could be obtained hence the gap in data points between the $8^{\text {th }}$ and $23^{\text {rd }}$ day.

All yogurts monitored maintained a $\log$ count around $6 \log 10(\mathrm{CFU} / \mathrm{mL})$ with values ranging from 6.51 to $6.88 \log 10(\mathrm{CFU} / \mathrm{mL})$. Having in mind the limited number of data points taken, when doing a statistical test no significant differences $(p>0.05)$ between the results with the controls were observed. It can be implied that the fruit preparations had 


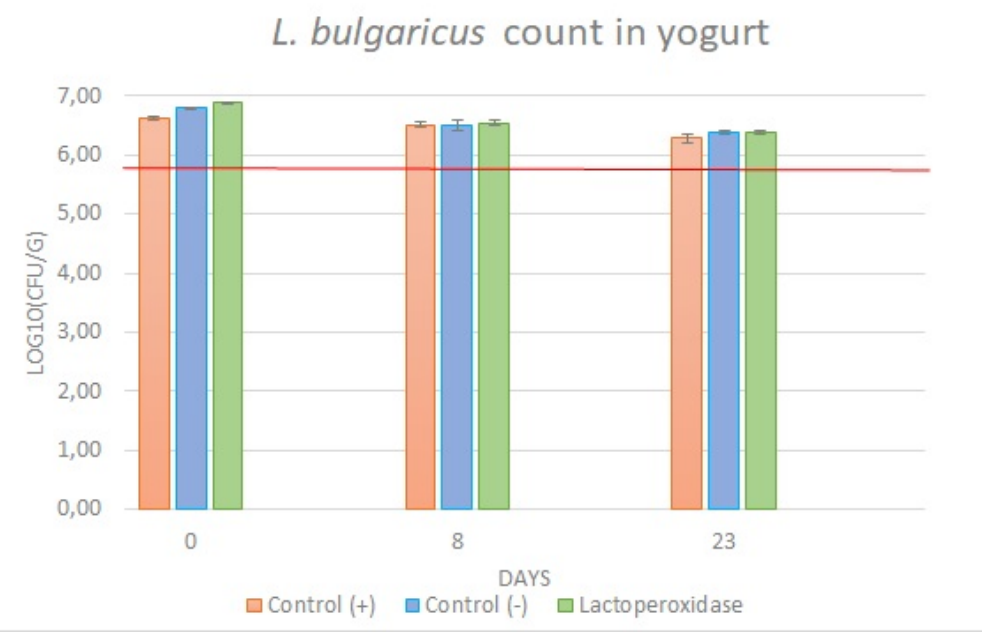

Figure 5.3: L. bulgaricus load of fruit preparations in dosed in yogurt containing lactoperoxidase, potassium sorbate (controlo (+)) or no antimicrobial (control (-)) during 23 days of cold storage at $4{ }^{\circ} \mathrm{C}$. The bullet points represent the average values and the bars the standard deviation. The red line represents the detection limit of the technique.

no negative effect in the lactic bateria count, which consequently means that is permitted to add them without affecting the lactic cultures present. As it happened in the previous Chapter the is a $2 \log 10$ count difference when comparing to the values in legislation and literature (Ministério, 1992; Donkor et al., 2006; Cruz et al., 2013). To confirm these, the total viable cell count was maintained at high levels $\left(10^{8} \mathrm{CFU} / \mathrm{g}\right)$ during two week storage when adding $5 \mathrm{mg} / \mathrm{kg}$ of lactoperoxidase system to conventional yogurt in Nakada's research (Nakada et al., 1996). In another point a view, other authors defend that apparent viscosity of yogurt is reduced having a smother texture when lactoperoxidase system is added to yogurt (Hirano et al., 1998), this parameters should be further tested in future work.

The results obtained of the fungal load on the yogurts is present in Figure 5.4. Results regarding the controls maintain the tendency observed in the previous subsection, no colony count was obtained when potassium sorbate was applied and on the second day of analysis the yogurt with no antimcrobial started to show signs of fungal contamination. Also, there is a clear boost in the log count of the yogurt containing lactoperoxidase at day $16(>4 \log 10(\mathrm{CFU} / \mathrm{g}))$. This fungal load is due to the presence of yeasts has it was observed by the colony conformations on the agar plates which may be justified because C. albicans was not affected by this enzyme once inoculated in goat milk (Seifu et al., 2005). Since when applied just on the fruit preparations this problem was not encountered it can be implied the change in matrix caused some lost in function of the enzyme. Also, dairy products contain high levels of protein, fat, and divalent cations, which can interfere 


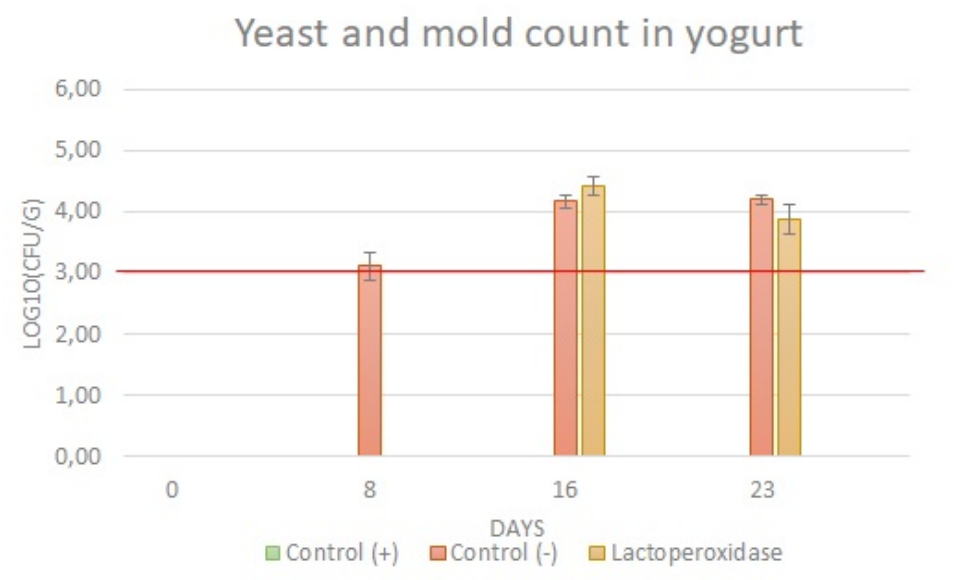

Figure 5.4: Fungal load of fruit preparations dosed in yogurt containing lactoperoxidase, potassium sorbate (controlo (+)) or no antimicrobial (control (-)) during 23 days of cold storage at $4{ }^{\circ} \mathrm{C}$. The bullet points represent the average values and the bars the standard deviation. The red line represents the detection limit of the technique.

with antimicrobials interacting with targets (Taylor, 2014). In addition it was observed by (Nakada et al., 1996) that the enzyme losses its activity over time during storage at $10{ }^{\circ} \mathrm{C}$ in yogurt. So, in conclusion the enzyme system could not substitute potassium sorbate since when the fruit preparations where applied to yogurt the fungal load was not controlled.

\subsection{Conclusions}

In this chapter the effect of lactoperoxidase in fruit preparations and dosed in yogurt was studied. In the fruit preparations lactoperoxidase successfully controlled its microbial load. Once applied to yogurt this could not be verified, however it did not interfere with the natural microflora of such.

In face of the obtained results this natural antimicrobial can not substitute potassium sorbate since it is not effective as a preservative and other natural antimicrobials such be tested like vanillin, since it showed such positive results in the previous chapter. 


\section{Chapter 6}

\section{Conclusions and future work}

\subsection{General conclusions}

Natural antimicrobials have been studied for many years and have shown potential as antifungal and antibacterial agents. Studies in vitro are abundant when comparing to the in situ ones. Because of this, the master thesis is focused in scanning the potential use of some antimicrobials like vanillin, olive hydrossol, citrus extracts, fermented syrup, lactoperoxidase and smoke aromas in fruit preparations doing in vitro and in situ tests.

For the most part of the natural antimicrobials showed little antifungal activity once tested in vitro until a maximum concentration of $0.5 \%(\mathrm{w} / \mathrm{w})$ against the most recurring fungus in tested raw materials and the Tortosendo factory. In any case, vanillin was able to prevent the growth of all isolated species at a maximum concentration of $0.5 \%(\mathrm{w} / \mathrm{w})$ while the organic citrus extract was not effective against all tested microorganisms, at maximum concentrations showed signs of inhibition in the most resistant fungus like Penicillium sp. .

Once vanillin and organic citrus extract were incorporated into fruit preparations at $0.5 \%(\mathrm{w} / \mathrm{w})$, the samples containing vanillin did not develop a detectable fungal load until day 45 of analysis. Maintaining its stability during the pasteurization process held at $90{ }^{\circ} \mathrm{C}$ during 4 min and being able to prevent growth of an artificial contamination of Penicillium sp. and Aspergillus sp.. Results regarding the organic citrus extract were not as positive, showing lack of resistance to the pasteurization process and was not able to control an artificial contamination with same success as vanillin. On a positive note, if added after the pasteurization process it could maintain the fungal load at 0 level during 44 days of cold storage at $4{ }^{\circ} \mathrm{C}$. But once these fruit preparations were added to yogurt, they did not interfere with yogurt natural microflora during 16 days of cold storage at $4{ }^{\circ} \mathrm{C}$. On the other hand, when it came to the organoleptic properties, the tasters preferred the stan- 
dard yogurt when comparing the yogurt containing the natural antimicrobials revealing a possible issue.

Lactoperoxidase was also tested in fruit preparations, FruIdentity, and successfully controlled its microbial load. Once applied to yogurt this could not be verified, however it did not interfere with the natural microflora of such.

In conclusion, organic citrus extract and lactoperoxidase, under the tested conditions, are not ideal to substitute potassium sorbate. Vanillin and potassium sorbate results were similar, showing that vanillin could potentially substitute these preservative.

\subsection{Future work}

In the current work, eight different natural antimicrobials were tested against the fungi isolated and identified by RT-PCR from the Torotosendo factory and the most contaminated raw materials. The not identified fungus were not tested and probably since they exist in the same places they can hypothetically be more resistant when comparing to the identified fungus and present a problem in fruit preparations, so they ought to be tested in vitro. Also for a most rigorous analysis, it is suggested to test the antifungal activity of the natural antimicrobials against the most recurring fungus in the food industry (Raybaudi-Massilia et al., 2009).

Additionally the technique, poisoned growing media technique, was not ideal to determined MIC values since the biomass used in each PDA Petri plate is not the same; Due to this important factor it can not stated with $100 \%$ certainty the values obtained of MIC (Klančnik et al., 2010; Balouiri et al., 2016), an alternative would be to use dilution methods since they are consider to be the most appropriate to determinate MIC values (Balouiri et al., 2016).

As a final note, the antibacterial activity should also be tested since most of the outbreaks of foodborne illness is cause by pathogenic bacteria like E. coli and Salmonella (Raybaudi-Massilia et al., 2009). Also in the fruit preparations and yogurt the bacterial growth should be monitored since it was only shown that vanillin can inhibit the growth of fungus. Since the $\mathrm{pH}$ is low, a value around 3 the antibacterial activity is not a concern, however this natural antimicrobial may be added to different products with different properties like $\mathrm{pH}$ and aw which could raise a concern regrading antibacterial safety. 


\section{References}

A. Acheampong, L. S. Borquaye, S. O. Acquaah, J. Osei-owusu, and G. K. Tuani, "Antimicrobial Activities of Some Leaves and Fruit Peels Hydrosols," International Journal of Chemical and Biomolecular Science, vol. 1, no. 3, pp. 158-162, 2015. 17, 19

M. Ahariz and P. Courtois, "Candida albicans susceptibility to lactoperoxidase-generated hypoiodite," Clinical, Cosmetic and Investigational Dentistry, vol. 2, pp. 69-78, 2010. 26

A. I. Al-Turki, "Antibacterial effect of thyme, peppermint, sage, black pepper and garlic hydrosols against Bacillus subtilis and Salmonella enteritidis," Journal of Food, Agriculture \& Environment, vol. 5, no. 2, pp. 92-94, 2007. 18, 19

N. Al-Zoreky, J. W. Ayres, and W. E. Sandine, "Antimicrobial activity of Microgard Against Food Spoilage and Pathogenic Microorganisms." Journal of Dairy Science, vol. 74 , no. 3, pp. $758-763$, 1991. 10, 30

G. Ayerst, "The effects of moisture and temperature on growth and spore germination in some fungi," Journal of Stored Products Research, vol. 5, pp. 127-141, 1969. 40

F. Azhdarzadeh and M. Hojjati, "O riginal Article Chemical Composition and Antimicrobial Activity of Leaf, Ripe and Unripe Peel of Bitter Orange ( Citrus aurantium ) Essential Oils," Nutrition and Food Sciences Research, vol. 3, no. 1, pp. 43-50, 2016. 30

M. Aziz and S. Karboune, "Natural Antimicrobial/Antioxidant Agents in Meat and Poultry Products as Well as Fruits and Vegetables: A Review," Critical Reviews in Food Science and Nutrition, vol. 8398, no. July, p. 0, 2016. 8

M. Balouiri, M. Sadiki, and S. K. Ibnsouda, "Methods for in vitro evaluating antimicrobial activity: A review," Journal of Pharmaceutical Analysis, vol. 6, no. 2, pp. 71-79, 2016. $24,31,58$

J. Bizzozeri, "Clean Label Top-of-Mind with Consumers in 2016," 2016. [Online]. Available: https://www.naturalproductsinsider.com/blogs/food-beverage-perspectives/ 2016/01/clean-label-top-of-mind-with-consumers-in-2016.aspx 5

A. Bocco, M.-E. Cuvelier, H. Richard, and C. Berset, "Antioxidant Activity and Phenolic Composition of Citrus Peel and Seed Extracts," Journal of Agricultural and Food Chemistry, vol. 46, no. 6, pp. 2123-2129, jun 1998. 14 
P. M. Bohra, A. S. Vaze, V. G. Pangarkar, and A. Taskar, "Adsorptive recovery of water soluble essential oil components," Journal of Chemical Technology AND Biotechnology, vol. 60, no. 1, pp. 97-102, may 1994. 17

R. Bortolomeazzi, N. Sebastianutto, R. Toniolo, and A. Pizzariello, "Comparative Evaluation of the Antioxidant Capacity of Smoke Flavouring Phenols by Crocin Bleaching Inhibition, DPPH Radical Scavenging and Oxidation Potential," Food Chemistry, vol. 100, no. 4, pp. 1481-1489, 2007. 11, 28

N. Boyraz and M. Özcan, "Antifungal effect of some spice hydrosols," Fitoterapia, vol. 76, no. 7-8, pp. 661-665, 2005. 18

S. Brul and P. Coote, "Preservative agents in foods Mode of action and microbial resistance mechanisms," International Journal of Food Microbiology, vol. 50, no. 1-2, pp. 1-17, sep 1999. 33

A. Buard, B. Carlton, F. Floch, and G. Simon, "Subchronic Toxicity, Mutagenicity and Allergenicity Studies of a Cultured Dextrose Food Product," Food and Chemical Toxicology, vol. 41, no. 5, pp. 689-694, may 2003. 10

S. a. Burt and R. D. Reinders, "Antibacterial Activity of Selected Plant Essential Oils Against Escherichia coli O157:H7." Letters in Applied Microbiology, vol. 36, no. 3, pp. 162-7, 2003. 7, 26

S. A. Burt, R. van der Zee, A. P. Koets, A. M. de Graaff, F. van Knapen, W. Gaastra, H. P. Haagsman, and E. J. A. Veldhuizen, "Carvacrol Induces Heat Shock Protein 60 and Inhibits Synthesis of Flagellin in Escherichia coli O157:H7." Applied and Environmental Microbiology, vol. 73, no. 14, pp. 4484-90, jul 2007. 13

D. R. Caccioni, M. Guizzardi, D. M. Biondi, Agatino Renda, and G. Ruberto, "Relationship between volatile components of citrus fruit essential oils and antimicrobial action on Penicillium digitatum and Penicillium italicum," International Journal of Food Microbiology, vol. 43, no. 1, pp. 73-79, 1998. 15, 30

P. Cerrutti and S. M. Alzamora, "Inhibitory Effects of Vanillin on Some Food Spoilage Yeasts in Laboratory Media and Fruit purées," International Journal of Food Microbiology, vol. 29, no. 2-3, pp. 379-386, apr 1996. 16, 33, 39

A. M. Cole, P. Weis, and G. Diamond, "Isolation and Characterization of Pleurocidin, an Antimicrobial Peptide in the Skin Secretions of Winter Flounder." The Journal of Biological Chemistry, vol. 272, no. 18, pp. 12 008-13, may 1997. 6

D. E. Conner and L. R. Beuchart, "Effects of Essential Oils from Plants on Growth of Food Spoilage Yeasts," Journal of Food Science, vol. 49, no. 2, pp. 429-434, mar 1984. 14

A. Cruz, W. Castro, J. Faria, H. Bolini, R. Celeghini, R. Raices, C. Oliveira, M. Freitas, C. Conte Júnior, and E. Mársico, "Stability of probiotic yogurt added with glucose 
oxidase in plastic materials with different permeability oxygen rates during the refrigerated storage," Food Research International, vol. 51, no. 2, pp. 723-728, 2013. 44, 54

R. I. Dave, P. Sharma, J. Julson, K. M uthukumarappan, and D. R. Henning, "Effectiveness of Microgard $\mathbb{R}$ in Controlling Escherichia coli O157:H7 and Listeria monocytogenes," Journal of food science and technology, vol. 40, no. 3, pp. 262-266, 2003. 10

P. M. Davidson, J. N. Sofos, and A. Branen, Antimicrobials in food, 3rd ed., P. M. Davidson, J. N. Sofos, and A. Branen, Eds. New York: CRC Press, 2005. 13, 30

P. M. Davidson, T. M. Taylor, and S. Schmidt E., "Chemical Preservatives and Natural Antimicrobial Compounds," in Food Microbiology; Fundamentals and Frontiers, 4th ed., R. Doyle, M.P. Buchannan, Ed. Washington, D. C.: ASM Press, 2013, ch. Chemical P, pp. 765-801. 7, 8, 11, 14, 22

B. de los Santos G de Paredes and F. Romero Muñoz, "Occurrence of Colletotrichum acutatum, Causal Organism of Strawberry Anthracnose in Southwestern Spain," Plant Disease, vol. 83, no. 3, pp. 301-301, mar 1999. 23

J. Delves-Broughton, "Natural Antimicrobials as Additives and Ingredients for the Preservation of Foods and Beverages," in Natural Food Additives, Ingredients and Flavourings, 1st ed., D. Baines and R. Seal, Eds. Elsevier, 2012, ch. 6, pp. 127-161. 7, 9, 10, $13,16,33$

J. Dijksterhuis, J. Houbraken, and R. A. Samson, "Fungal Spoilage of Crops and Food," Agricultural Applications, pp. 35-56, 2013. 22

O. Donkor, A. Henriksson, T. Vasiljevic, and N. Shah, "Effect of acidification on the activity of probiotics in yoghurt during cold storage," International Dairy Journal, vol. 16, no. 10 , pp. $1181-1189$, oct $2006.44,54$

S. C. G. dos Santos, "Antifungal and Functional Properties of Polyphenols in Food Products," Master, Faculty of Engineering of the University of Porto, 2016. 22, 30

M. Dufour, "Development of a method to quantify in vitro the synergistic activity of "natural" antimicrobials," International Journal of Food Microbiology, vol. 85, no. 3, pp. 249-258, aug 2003. 26, 27

K. Düring, P. Porsch, A. Mahn, O. Brinkmann, and W. Gieffers, "The Non-enzymatic Microbicidal Activity of Lysozymes," FEBS Letters, vol. 449, no. 2-3, pp. 93-100, apr 1999. 8

F. Elotmani and O. Assobhei, "In vitro inhibition of microbial flora of fish by nisin and lactoperoxidase system," Letters in Applied Microbiology, vol. 38, no. 1, pp. 60-65, 2004. 8,26 
D. Elsser-Gravesen and A. Elsser-Gravesen, "Biopreservatives," in Biotechnology of Food and Feed Additives, 143rd ed., H. Zorn and P. Czermak, Eds. Springer Berlin Heidelberg, 2014, ch. 2, pp. 29-49. 9, 10, 30

European Parliament and Council of the European Union, "Regulation (EC) No 1332/2008 of the European Parliament and of the Council of 16 December 2008 on food enzymes and amending Council Directive 83/417/EEC, Council Regulation (EC) No 1493/1999, Directive 2000/13/EC, Council Directive 2001/112/EC and(..)," Official Journal of the European Union L 354, vol. 51, no. 1332, pp. 7-15, 2008. 8

FI Europe, "Clean Labels - From Niche Trend to New Standard," 2015. [Online]. Available: http://www.prnewswire.com/news-releases/ clean-labels---from-niche-trend-to-new-standard-537392691.html 5

K. Fisher and C. Phillips, "The effect of lemon, orange and bergamot essential oils and their components on the survival of Campylobacter jejuni, Escherichia coli O157, Listeria monocytogenes, Bacillus cereus and Staphylococcus aureus in vitro and in food systems," Journal of Applied Microbiology, vol. 101, no. 6, pp. 1232-1240, dec 2006. 15

"Potential antimicrobial uses of essential oils in food: is citrus the answer?" Trends in Food Science \& Technology, vol. 19, no. 3, pp. 156-164, mar 2008. 15, 26, 30, 33, 46

D. J. Fitzgerald, M. Stratford, M. J. Gasson, and A. Narbad, "The Potential Application of Vanillin in Preventing Yeast Spoilage of Soft Drinks and Fruit Juices," Journal of Food Protection, vol. 67, no. 2, pp. 391-395, 2004. 16, 39, 42

Frulact, "Frulact: History," 2016. [Online]. Available: http://www.frulact.pt/cms/index. php?id=4\{\&\}L=7 1

C. C. Fuglsang, C. Johansen, S. Christgau, and J. Adler-Nissen, "Antimicrobial enzymes: Applications and future potential in the food industry," Trends in Food Science \& Technology, vol. 6, no. 12, pp. 390-396, 1995. 19

D. Y. C. Fung, S. Taylor, and J. Kahan, "Effects of butylated hydroxyanisole (bha) and butylated hydroxytoluene (bht) on growth and aflatoxin production of Aspergillus flavus," Journal of Food Safety, vol. 1, no. 1, pp. 39-51, aug 1977. 13

M. G. Gänzle, C. Hertel, and W. P. Hammes, "Resistance of Escherichia coli and Salmonella Against Nisin and Curvacin A," International Journal of Food Microbiology, vol. 48, no. 1, pp. 37-50, 1999. 6

J. Guarro, I. Pujol, C. Aguilar, C. Llop, and J. Fernandez-Ballart, "Inoculum preparation for in-vitro susceptibility testing of filamentous fungi." Journal of Antimicrobial Chemotherapy, vol. 42, no. 3, pp. 385-387, sep 1998. 35 
Y.-O. Hay, M. A. Abril Sierra, M. Tellez, L. G. Sequeda C, A. N. Tellez A, C. Bonnafous, and C. Raynaud, "Phytochemical, antioxidant and antimicrobial parameters of essential oils and hydrosols of colombian Thyme and Rosemary obtained using two different steam distillation methods," International Journal of Phytocosmetics and Natural Ingredients, vol. 2, no. 1, pp. 7-7, 2015. 17, 19

J. Hilton, "Clean Label Is on the Rise," 2016. [Online]. Available: https: //www.naturalproductsinsider.com/articles/2016/09/clean-label-is-on-the-rise.aspx 5

R. Hirano, M. Hirano, M. Oooka, S. Dosako, I. Nakajima, and K. Igoshi, "Lactoperoxidase Effects on Rheological Properties of Yogurt," Chemistry/Biochemistry, vol. 63, no. 1 , pp. 35-38, 1998. 54

R. A. Holley and D. Patel, "Improvement in Shelf-life and Safety of Perishable Foods by Plant Essential Oils and Smoke Antimicrobials," Food Microbiology, vol. 22, no. 4, pp. 273-292, 2005. 10, 11, 14

A. M. Hosein, F. Breidt, and C. E. Smith, "Modeling the Effects of Sodium Chloride, Acetic Acid, and Intracellular pH on Survival of Escherichia coli O157:H7," Applied and Environmental Microbiology, vol. 77, no. 3, pp. 889-895, feb 2011. 14

Y. H. Y. H. Hui, Ed., Handbook of Food Products Manufacturing, 1st ed. WileyInterscience, 2007. 20

J. Hussien, C. Teshale, and J. Mohammed, "Assessment of the antimicrobial effetcs of some Ethipian Aromatic Spice and Herb Hydrosols.pdf,” pp. 635-640, 2011. 18

S. Inouye, S. Abe, H. Yamaguchi, and M. Asakura, "Comparative study of antimicrobial and cytotoxic effects of selected essential oils by gaseous and solution contacts," 2003. 16,29

S. Inouye, M. Takahashi, and S. Abe, "Inhibitory Activity of Hydrosols, Herbal Teas and Related Essential Oils Against Filament Formation and the Growth of Candida albicans," Nippon Ishinkin Gakkai Zasshi, vol. 50, pp. 243-251, 2009. 17, 18, 26

International Organization for Standardization, "Microbiology of food and animal feeding stuffs - Horizontal method for the enumeration of yeasts and moulds - Part 1: Colony count technique in products with water activity greater than $0,95, " 2008$. 35, 36, 37, $44,50,51$

B. M. Jacob, K. Essy Antony, B. Sreekumar, and M. Haridas, "Thiocyanate mediated antifungal and antibacterial property of goat milk lactoperoxidase," Life Sciences, vol. 66, no. 25 , pp. 2433-2439, may 2000. 26, 27

J. M. Jay and G. M. Rives, "Antimicrobial Activity of Some Food Flavoring Compounds," Journal of Food Safety, vol. 6, no. 2, pp. 129-139, 1984. 16

S.-M. Jeong, S.-Y. Kim, D.-R. Kim, S.-C. Jo, K. C. Nam, D. U. Ahn, and S.-C. Lee, "Effect of Heat Treatment on the Antioxidant Activity of Extracts from Citrus Peels," 
Journal of Agricultural and Food Chemistry, vol. 52, no. 11, pp. 3389-3393, jun 2004. 41

V. K. Juneja, H. P. Dwivedi, and X. Yan, "Novel Natural Food Antimicrobials," Annual Review of Food Science and Technology, vol. 3, no. 1, pp. 381-403, 2012. 5, 6, 7

S. P. Kim, M. Y. Kang, J. C. Park, S. H. Nam, and M. Friedman, "Rice Hull Smoke Extract Inactivates Salmonella Typhimurium in Laboratory Media and Protects Infected Mice against Mortality," Journal of Food Science, vol. 77, no. 1, pp. M80-M85, jan 2012. 12,28

A. Klančnik, S. Piskernik, B. Jeršek, and S. S. Možina, "Evaluation of diffusion and dilution methods to determine the antibacterial activity of plant extracts," Journal of Microbiological Methods, vol. 81, no. 2, pp. 121-126, may 2010. 27, 31, 58

K. D. Kussendrager and a. C. van Hooijdonk, "Lactoperoxidase: Physico-chemical Properties, Occurrence, Mechanism of Action and Applications." The British journal of nutrition, vol. 84 Suppl 1, no. 2000, pp. S19-S25, 2000. 8, 26, 49

N.-k. Lee and H.-d. Paik, "Status ,Antimicrobial Mechanism, and Regulation of Natural Preservatives in Livestock Food Systems," Korean Journal Food Science of Animal Resources, vol. 36, no. 4, pp. 547-557, 2016. 6, 9

J. Legan and P. Voysey, "Yeast spoilage of bakery products and ingredients," Journal of Applied Bacteriology, vol. 70, no. 5, pp. 361-371, may 1991. 21, 38

S. Leleu, L. Herman, M. Heyndrickx, K. De Reu, C. Michiels, J. De Baerdemaeker, and W. Messens, "Effects on Salmonella Shell Contamination and Trans-shell Penetration of Coating Hens' eggs With Chitosan," International Journal of Food Microbiology, vol. 145, no. 1, pp. 43-48, jan 2011. 6

M.-J. Lemay, J. Choquette, P. J. Delaquis, C. Gariépy, N. Rodrigue, and L. Saucier, "Antimicrobial Effect of Natural Preservatives in a Cooked and Acidified Chicken Meat Model," International Journal of Food Microbiology, vol. 78, no. 3, pp. 217-226, oct 2002. 10

J. M. Lingbeck, P. Cordero, C. A. O’Bryan, M. G. Johnson, S. C. Ricke, and P. G. Crandall, "Functionality of Liquid Smoke as an All-natural Antimicrobial in Food Preservation," Meat Science, vol. 97, no. 2, pp. 197-206, 2014. 11, 12

M. Lis-Balchin, H. Steyrl, and E. Krenn, "The Comparative Effect of Novel Pelargonium Essential Oils and their Corresponding Hydrosols as Antimicrobial Agents in a Model Food System," Phytotherapy Research, vol. 17, no. 1, pp. 60-65, jan 2003. 17, 19

E. J. Loo Van, D. Babu, P. G. Crandall, and S. C. Rickle, "Screening of Commercial and Pecan Shell-Extracted Liquid Smoke Agents as Natural Antimicrobials against Foodborne..." Journal of Food Protection, vol. 75, no. 6, pp. 1148-1152, 2012. 12, 28 
A. López-Malo, S. Alzamora, and A. Argaiz, "Effect of Natural Vanillin on Germination Time and Radial Growth of Molds in Fruit-based Agar Systems," Food Microbiology, vol. 12, pp. 213-219, feb 1995. 7, 13, 16, 27, 33, 39

A. López-Malo, S. Maris Alzamora, and E. Palou, "Aspergillus flavus growth in the presence of chemical preservatives and naturally occurring antimicrobial compounds," International Journal of Food Microbiology, vol. 99, no. 2, pp. 119-128, 2005. 16

A. Lourens-Hattingh and B. C. Viljoen, "Yogurt as probiotic carrier food," International Dairy Journal, vol. 11, no. 1-2, pp. 1-17, jan 2001. 34

A. Lucera, C. Costa, A. Conte, and M. A. Del Nobile, "Food Applications of Natural Antimicrobial Compounds." Frontiers in Microbiology, vol. 3, p. 287, 2012.7

F. Makki and T. Durance, "Thermal Inactivation of Lysozyme as Influenced by pH, Sucrose and Sodium Chloride and Inactivation and Preservative Effect in Beer," Food Research International, vol. 29, no. 7, pp. 635-645, 1996. 8

E. M. Martin, C. A. O’Bryan, R. Y. Lary, C. L. Griffis, K. L. Vaughn, J. A. Marcy, S. C. Ricke, and P. G. Crandall, "Spray Application of Liquid smoke to Reduce or Eliminate Listeria monocytogenes Surface Inoculated on Frankfurters," Meat Science, vol. 85, no. 4, pp. 640-644, aug 2010. 12

M. C. Messina, "The Effect of Liquid Smoke on Listeria monocytogenes," Ph.D. dissertation, The University of Arizona., 1988. 12, 28

M. Michael, R. K. Phebus, and K. A. Schmidt, "Impact of a plant extract on the viability of Lactobacillus delbrueckii ssp. bulgaricus and Streptococcus thermophilus in nonfat yogurt," International Dairy Journal, vol. 20, no. 10, pp. 665-672, 2010. 37, 44, 51

P. J. Milly, R. T. Toledo, and S. Ramakrishnan, "Determination of Minimum Inhibitory Concentrations of Liquid Smoke Fractions," Journal of Food Science, vol. 70, no. 1, pp. M12-M17, jan 2005. 11, 28

S. Min and J. M. Krochta, "Inhibition of Penicillium commune by Edible Whey Protein Films Incorporating Lactoferrin, Lacto-ferrin Hydrolysate, and Lactoperoxidase Systems," Journal of Food Science, vol. 70, no. 2, pp. M87-M94, mar 2005. 8, 9

S. Min, L. J. Harris, and J. M. Krochta, "Antimicrobial Effects of Lactoferrin, Lysozyme, and the Lactoperoxidase System and Edible Whey Protein Films Incorporating the Lactoperoxidase System Against Salmonella enterica and Escherichia coli O157:H7," Journal of Food Science, vol. 70, no. 7, pp. m332-m338, sep 2005. 9

A. E. D. C. E. T. Ministério, "Diário da República - I Série B nº 169 Portaria n n $^{0}$ 742/92 de 24 de Julho," pp. 3462-3465, 1992. 44, 54

N. Montazeri, A. C. Oliveira, B. H. Himelbloom, M. B. Leigh, and C. a. Crapo, "Chemical Characterization of Commercial Liquid Smoke Products." Food Science \& Nutrition, vol. 1, no. 1, pp. 102-15, 2013. 11, 19 
M. d. R. Moreira, M. Pereda, N. E. Marcovich, and S. I. Roura, "Antimicrobial Effectiveness of Bioactive Packaging Materials from Edible Chitosan and Casein Polymers: Assessment on Carrot, Cheese, and Salami," Journal of Food Science, vol. 76, no. 1, pp. M54-M63, jan 2011. 6

M. Moreira, A. Ponce, C. del Valle, and S. Roura, "Inhibitory parameters of essential oils to reduce a foodborne pathogen," 2005. 15

S. Moufida and B. Marzouk, "Biochemical characterization of blood orange, sweet orange, lemon, bergamot and bitter orange," Phytochemistry, vol. 62, no. 8, pp. 12831289, 2003. xv, 14, 15

M. Nakada, S. Dosako, R. Hirano, M. Oooka, and I. Nakajima, "Lactoperoxidase Suppresses Acid Production in yoghurt during storage under refrigeration," International Dairy Journal, vol. 6, no. 1, pp. 33-42, jan 1996. 54, 55

A. Oliveira, E. M. C. Alexandre, M. Coelho, C. Lopes, D. P. F. Almeida, and M. Pintado, "Incorporation of strawberries preparation in yoghurt: Impact on phytochemicals and milk proteins," Food Chemistry, vol. 171, pp. 370-378, 2015. 49

M. Özcan, "Effect of Spice Hydrosols on the Growth of Aspergillus parasiticus NRRL 2999 Strain," Journal of Medicinal Food, vol. 8, no. 2, pp. 275-278, jun 2005. 18

D. K. Pandey, N. N. Tripathi, R. Tripathi, and S. N. Dixit, "Fungitoxic and phytotoxic properties of the essential oil of Hyptis suaveolens," Journal of Plant Diseases and Protection, vol. 89, no. 6, pp. 344-349, 1981. 24

S.-I. Park, S. D. Stan, M. A. Daeschel, and Y. Zhao, "Antifungal Coatings on Fresh Strawberries ( Fragaria ananassa ) to Control Mold Growth During Cold Storage," Journal of Food Science, vol. 70, no. 4, pp. 202-207, 2005. 41

V. Penney, G. Henderson, C. Blum, and P. Johnson-Green, "The potential of phytopreservatives and nisin to control microbial spoilage of minimally processed fruit yogurts," Innovative Food Science and Emerging Technologies, vol. 5, no. 3, pp. 369-375, 2004. 44

A. V. S. Perumalla and N. S. Hettiarachchy, "Green tea and grape seed extracts - Potential applications in food safety and quality," Food Research International, vol. 44, no. 4, pp. 827-839, 2011. 33

J. I. Pitt and A. D. Hocking, Fungi and Food Spoilage, 3rd ed. Springer, 2009. 22

L. Popper and D. Knorr, "Inactivation of Yeast and Filamentous Fungi by the Lactoperoxidase-hydrogen peroxide-thiocyanate-system," Die Nahrung, vol. 41, no. 1, pp. 29-33, 1997. 53

S. Ramakrishnan and P. Moeller, "Liquid Smoke: Product of Hardwood Pyrolysis." Fuel Chemistry Division Preprints, vol. 47, no. 1, 2002. 11, 20, 29 
R. M. Raybaudi-Massilia, J. Mosqueda-Melgar, R. Soliva-Fortuny, and O. MartínBelloso, "Control of Pathogenic and Spoilage Microorganisms in Fresh-cut Fruits and Fruit juices by Traditional and Alternative Natural Antimicrobials," Comprehensive Reviews in Food Science and Food Safety, vol. 8, no. 3, pp. 157-180, 2009. 48, 58

Z. Rezazadeh, M. H. Marhamatizadeh, and M. Radi, "Effect of Vanillin on Lactobacillus acidophilus And Bifidobacterium bifidum And Evaluation of Its Physicochemical and Sensory Properties in Probiotics Yoghurt," Journal of Applied Environmental and Biological Sciences, vol. 4, no. 11S, pp. 191-197, 2015. 44

S. C. Ricke, "Perspectives on the Use of Organic Acids and Short Chain Fatty Acids as Antimicrobials," Poultry Science, vol. 82, no. 4, pp. 632-939, 2003. 14

H. P. V. Rupasinghe, J. Boulter-Bitzer, T. Ahn, and J. A. Odumeru, "Vanillin Inhibits Pathogenic and Spoilage Microorganisms in vitro and Aerobic Microbial Growth in Fresh-cut Apples," Food Research International, vol. 39, no. 5, pp. 575-580, 2006.7 , $16,17,33$

O. Sağdiç and M. Özcan, "Antibacterial activity of Turkish spice hydrosols," Food Control, vol. 14, no. 3, pp. 141-143, 2002. 17, 18

P. Saiyasombati and G. B. Kasting, "Two-stage kinetic analysis of fragrance evaporation and absorption from skin," International Journal of Cosmetic Science, vol. 25, no. 5, pp. 235-243, oct 2003. 16,39

Z. Schelz, J. Molnar, and J. Hohmann, "Antimicrobial and antiplasmid activities of essential oils," Fitoterapia, vol. 77, no. 4, pp. 279-285, 2006. 15

E. Seifu, E. M. Buys, and E. F. Donkin, "Significance of the lactoperoxidase system in the dairy industry and its potential applications: A review," Trends in Food Science and Technology, vol. 16, no. 4, pp. 137-154, 2005. 49, 54

D. A. L. Seiler, "Bakery products," in Principles and Applications of Modified Atmosphere Packaging of Foods. Boston, MA: Springer US, 1999, pp. 135-157. 21

S. Sharma, "Food Preservatives and their Harmfull Effect," International Journal of Scientific and Research Publications, vol. 5, no. 4, pp. 5-6, 2015. 6

W. Si, J. Gong, R. Tsao, T. Zhou, H. Yu, C. Poppe, R. Johnson, and Z. Du, "Antimicrobial activity of essential oils and structurally related synthetic food additives towards selected pathogenic and beneficial gut bacteria," Journal of Applied Microbiology, vol. 100, no. 2, pp. 296-305, feb 2006. 15

P. Šimko, "Factors Affecting Elimination of Polycyclic Aromatic Hydrocarbons from Smoked Meat Foods and Liquid Smoke Flavorings," Molecular Nutrition \& Food Research, vol. 49, no. 7, pp. 637-647, jul 2005. 11

D. C. Smith, S. Forland, E. Bachanos, M. Matejka, and V. Barrett, "Qualitative Analysis of Citrus Fruit Extracts by GC/MS: An Undergraduate Experiment," The Chemical Educator, vol. 6, no. 1, pp. 28-31, feb 2001. 14 
J. P. Smith, D. P. Daifas, W. El-Khoury, J. Koukoutsis, and A. El-Khoury, "Shelf Life and Safety Concerns of Bakery Products-A Review," Critical Reviews in Food Science and Nutrition, vol. 44, no. 1, pp. 19-55, 2004. 21

J. N. Sofos and I. Geornaras, "Overview of current meat hygiene and safety risks and summary of recent studies on biofilms, and control of Escherichia coli O157:H7 in nonintact, and Listeria monocytogenes in ready-to-eat, meat products," Meat Science, vol. 86 , no. 1, pp. 2-14, 2010. 22

M. M. Tajkarimi, S. A. Ibrahim, and D. O. Cliver, "Antimicrobial Herb and Spice Compounds in Food," Food Control, vol. 21, no. 9, pp. 1199-1218, 2010. 6, 7, 17

H. Takahashi, S. Kuramoto, S. Miya, H. Koiso, T. Kuda, and B. Kimura, "Use of Commercially Available Antimicrobial Compounds for Prevention of Listeria monocytogenes Growth in Ready-to-Eat Minced Tuna and Salmon Roe during Shelf Life," Journal of Food Protection, vol. 74, no. 6, pp. 994-998, jun 2011. 2, 8

T. M. Taylor, Handbook of Natural Antimicrobials for Food Safety and Quality, 1st ed., T. M. Taylor, Ed. $\quad$ Elsevier, 2014. 9, 14, 19, 49, 55

T. M. Taylor and A. A. Lathrop, "Evaluation of Antimicrobials and Salt Replacers for Use in Low-Sodium Dairy Products," Journal of Food Safety, vol. 35, no. 1, pp. 32-40, feb 2015. 26, 27

V. E. Tikhonov, E. A. Stepnova, V. G. Babak, I. A. Yamskov, J. Palma-Guerrero, H.-B. Jansson, L. V. Lopez-Llorca, J. Salinas, D. V. Gerasimenko, I. D. Avdienko, and V. P. Varlamov, "Bactericidal and Antifungal Activities of a Low Molecular Weight Chitosan and its N-/2(3)-(dodec-2-enyl)succinoyl/-derivatives," Carbohydrate Polymers, vol. 64, no. 1 , pp. 66-72, apr 2006. 6

B. K. Tiwari, V. P. Valdramidis, C. P. O’ Donnell, K. Muthukumarappan, P. Bourke, and P. J. Cullen, "Application of Natural Antimicrobials for Food Preservation," Journal of Agricultural and Food Chemistry, vol. 57, no. 14, pp. 5987-6000, jul 2009. 6, 7, 8, 9

B. Tomadoni, G. Viacava, L. Cassani, M. R. Moreira, and A. Ponce, "Novel biopreservatives to enhance the safety and quality of strawberry juice," Journal of Food Science and Technology, vol. 53, no. 1, pp. 281-292, 2016. 17, 42

F. Tornuk, H. Cankurt, I. Ozturk, O. Sagdic, O. Bayram, and H. Yetim, "Efficacy of various plant hydrosols as natural food sanitizers in reducing Escherichia coli O157:H7 and Salmonella Typhimurium on fresh cut carrots and apples," International Journal of Food Microbiology, vol. 148, no. 1, pp. 30-35, 2011. 17

V. Touch, S. Hayakawa, S. Yamada, and S. Kaneko, "Effects of a Lactoperoxidasethiocyanate-hydrogen Peroxide System on Salmonella enteritidis in animal or vegetable foods," International Journal of Food Microbiology, vol. 93, no. 2, pp. 175-183, jun 2004. 53 
A. A. L. Tribst, A. D. S. Sant'Ana, and P. R. de Massaguer, "Review: Microbiological Quality and Safety of Fruit Juices-Past, Present and Future Perspectives." Critical Reviews in Microbiology, vol. 35, no. 4, pp. 310-339, 2009. 13, 21, 22

Vercammen A, P. Pechova, L. Delanote, and Houf K, "Liquid Smoke, an Effective Antimicrobial for the Preservation of Cooked Meats Ham Material and Methods." 13

A. L.-M. Vigil, E. Palou, and S. M. Alzamora, "Naturally Occuring Compounds-Plant Sources," in Antimicrobials in food, 3rd ed., P. M. Davidson, J. N. Sofos, and A. Branen, Eds. New York: Taylor and Francis Group, LLC, 2005, ch. 14, pp. 429-453. 13, 16

S. M. Vitt, B. H. Himelbloom, and C. A. Crapo, "Inhibition of listeria innocua and 1. monocytogenes in a Laboratory Medium and Cold-smoked Salmon Containing Liquid Smoke," Journal of Food Safety, vol. 21, no. 2, pp. 111-125, jun 2001. 11

M. von Staszewski and R. J. Jagus, "Natural Antimicrobials: Effect of Microgard ${ }^{\mathrm{TM}}$ and Nisin Against Listeria innocua in Liquid Cheese Whey," International Dairy Journal, vol. 18, no. 3, pp. 255-259, mar 2008. 10

M. Watrous, "Trend of the Year I Clean Label," 2015. [Online]. Available: http://features.foodbusinessnews.net/corporateprofiles/2015/trend-index.html 5

a. Welk, C. Meller, R. Schubert, C. Schwahn, A. Kramer, and H. Below, "Effect of lactoperoxidase on the antimicrobial effectiveness of the thiocyanate hydrogen peroxide combination in a quantitative suspension test." BMC microbiology, vol. 9, p. 134, 2009. 26,27

F. Y. Yener, F. Korel, and A. Yemenicioğlu, "Antimicrobial Activity of Lactoperoxidase System Incorporated into Cross-Linked Alginate Films," Journal of Food Science, vol. 74, no. 2, pp. M73-M79, mar 2009. 9

T. Yuan, L. Li, Y. Zhang, and N. P. Seeram, "Pasteurized and sterilized maple sap as functional beverages: Chemical composition and antioxidant activities," Journal of Functional Foods, vol. 5, no. 4, pp. 1582-1590, 2013. 39, 42

H. Zuckerman and R. Ben Avraham, "Control of Growth of L. monocytogenes in Fresh Salmon using Microgard ${ }^{\mathrm{TM}}$ and Nisin," LWT - Food Science and Technology, vol. 35, no. 6 , pp. 543-548, sep 2002. 10 


\section{Appendix A}

\section{In vitro assessment of the antifungal activity of the natural antimicrobials}

A.0.1 Tables of the isolated microorganisms 
Table A.1: Fungi isolated when characterizing raw materials and different zones Tortosendo Industry. The number correspondent to each plate is related with the source of isolation hence just being a reference. NI represents the fungi that could not be identified by RT-PCR.

\begin{tabular}{|c|c|c|}
\hline Number & Photograph & Microorganisms \\
\hline 1 & & Penicillium sp. \\
\hline 4 & & Cladosporium sp. \\
\hline 7 & & Aspergillus sp. \\
\hline 8 & & $\begin{array}{c}\text { A. chevalieri } \\
\text { A. amstelodami } \\
\text { A. heterocaryoticus }\end{array}$ \\
\hline 9 & & $\mathrm{NI}$ \\
\hline 15 & & Pseudomonas sp. \\
\hline 17 & & M. piriformis \\
\hline 19 & & P. glomerata \\
\hline 20 & & $\begin{array}{l}\text { NI } \\
\text { Ponicillimen }\end{array}$ \\
\hline $8 A$ & & $\begin{array}{l}\text { P. spinulosum } \\
\text { P. glabrum }\end{array}$ \\
\hline $9 A$ & & E. nigrum \\
\hline $10 \mathrm{~A}$ & & NI \\
\hline $11 \mathrm{~A}$ & & Penicillium sp. \\
\hline $12 \mathrm{~A}$ & & NI \\
\hline $14 \mathrm{~A}$ & $\Delta$ & Cladosporium sp. \\
\hline
\end{tabular}


Table A.2: Yeasts isolated when characterizing raw materials and different zones Tortosendo Industry. The number correspondent to each plate is related with the source of isolation hence just being a reference. NI represents the microorganisms that could not be identified by RT-PCR.

\begin{tabular}{|c|c|c|}
\hline Number & Photograph & Microorganisms \\
\hline 6 & & NI \\
\hline 10 & & Cryptococcus sp. \\
\hline 21 & & P. anomala \\
\hline 22 & & C. santamarie \\
\hline $2 A$ & 2 & $\mathrm{NI}$ \\
\hline $3 A$ & & Pichia sp. \\
\hline $5 A$ & & NI \\
\hline $13 A$ & & $\mathrm{NI}$ \\
\hline
\end{tabular}




\title{
Appendix B
}

\section{Testing the selected natural}

antimicrobials in fruit preparations and yogurt

\author{
B.0.1 Questionnaire
}




\section{Amostra 1}

Avaliação sensorial do iogurte com frutos silvestres SEMPRE em comparação com o padrão:

1.

\begin{tabular}{|c|c|c|c|}
\hline Características & Menos & Igual & Mais \\
\hline Acidez & & & \\
\hline Doçura & & & \\
\hline Adstringência & & & \\
\hline
\end{tabular}

2. Sabor em relação ao padrão:
Igual
Pouco diferente
Muito diferente

3. Sabor mais agradável:
Padrão
Amostra 1
Indiferente

4. Qual compraria? : (padrão/amostra1/nenhum)

Figure B.1: Example of a questionnaire taken by the subjects when tasting the yogurt with the natural antimicrobials. Every person did two, one for the yogurt with the fruit preparation with vanillin and the one for the fruit preparation with the citrus extract. The questionnaires focus on the comparison of the fruit preparation with potassium sorbate with the ones containing the natural antimicrobials. 